Universidad de Lima

Escuela de Posgrado

Maestría en Derecho Empresarial

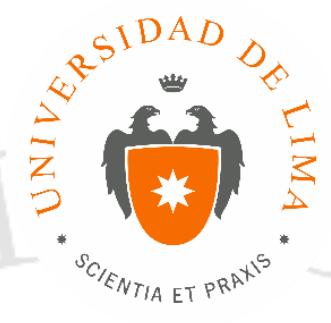

\title{
LA FIGURA DE LA ASISTENCIA \\ FINANCIERA EN LA LEY GENERAL DE SOCIEDADES PERUANA
}

Trabajo de investigación para optar el Grado Académico de Maestro en

Derecho Empresarial

\section{Johanna Giuliana Rossi Villamil}

20051027

\section{Asesor}

Eduardo Leturia López

Lima - Perú

Marzo, 2018 


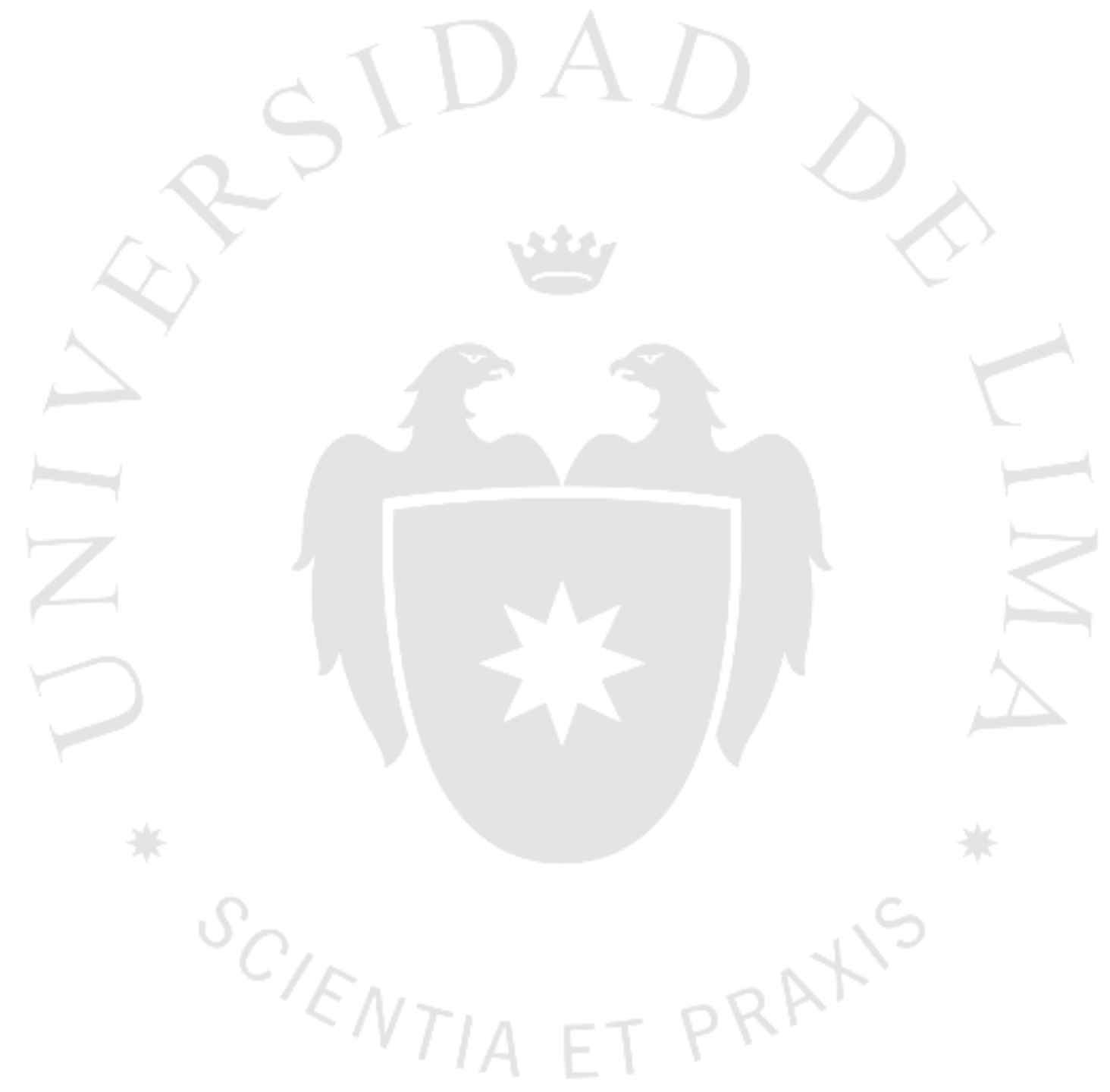




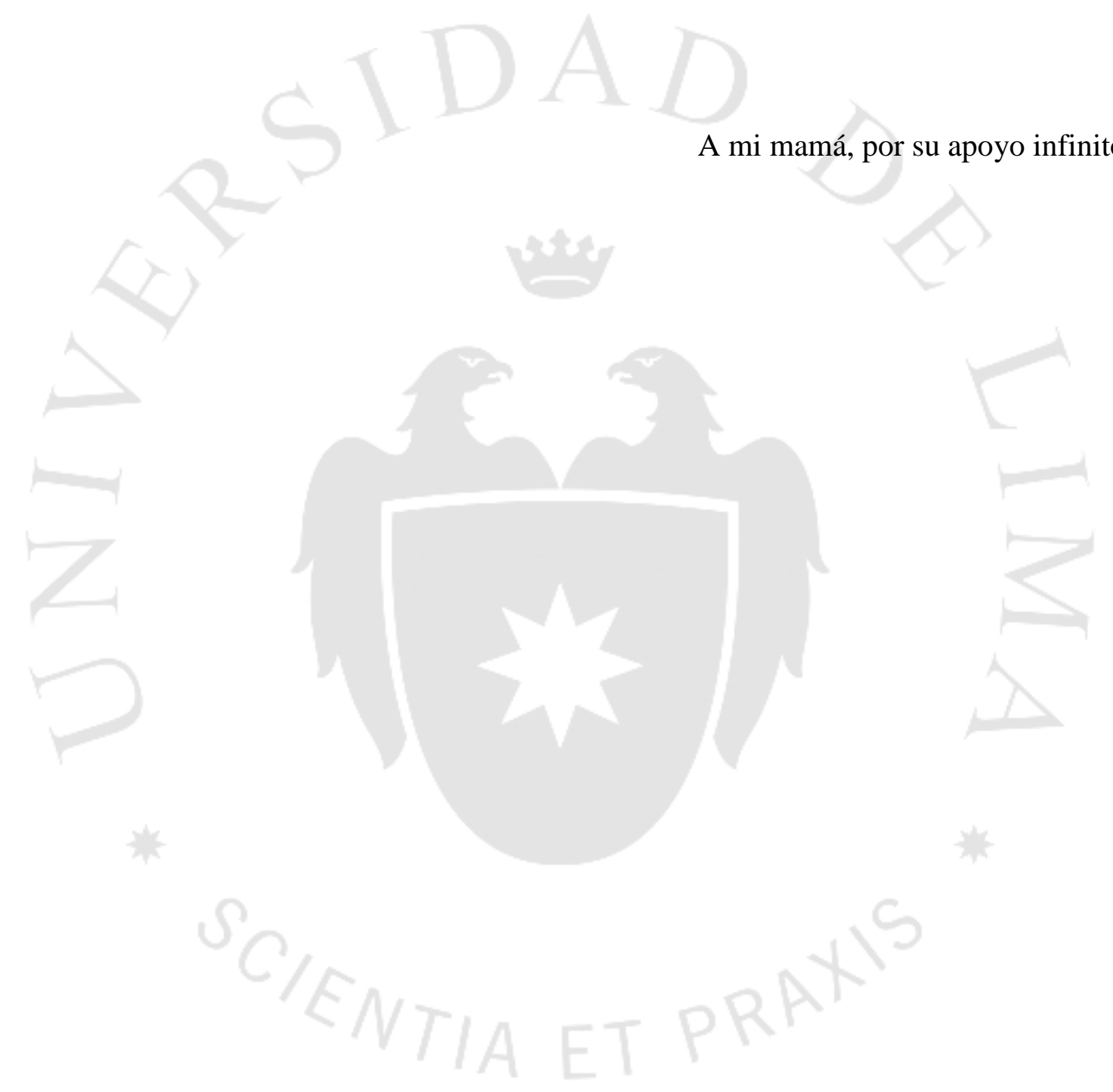




\section{LA FIGURA DE LA ASISTENCIA}

\section{FINANCIERA EN LEY GENERAL DE}

SOCIEDADES PERUANA 


\section{TABLA DE CONTENIDOS}

INTRODUCCIÓN 1

\section{CAPÍTULO I: ASPECTOS GENERALES SOBRE LA FIGURA DE LA} ASISTENCIA FINANCIERA .............................................................................4

1.1 Noción doctrinaria de la figura de la Asistencia Financiera ..................4

1.2 Legislación internacional sobre la figura de la Asistencia Financiera....6

1.2.1 Regulación británica .................................................................

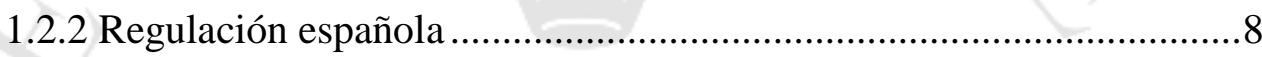

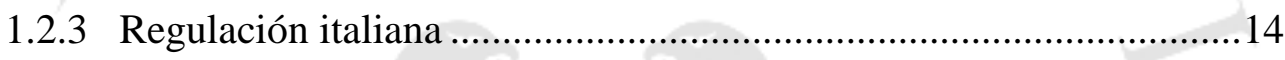

1.3. Regulación de la figura de la Asistencia Financiera de acuerdo a la Ley

General de Sociedades Peruana ..............................................................15

1.3.1 Análisis del artículo $106^{\circ}$ de la Ley General de Sociedades Peruana: 16

1.3.1.1 Análisis doctrinario sobre la Asistencia Financiera: .....................16

1.3.1.2 Análisis legal sobre los supuestos de Asistencia Financiera Prohibida .21

1.3.2 ¿Los Leveraged buyouts califican como Asistencia Financiera prohibida?

1.3.3 Análisis de otras figuras que pueden calificar como Asistencia Financiera Prohibida. .35

1.4 Algunas conclusiones preliminares a manera de recapitulación .37

\section{CAPÍTULO II: ASPECTOS CRÍTICOS A LA FIGURA DE LA ASISTENCIA FINANCIERA

2.1. Posibles justificaciones para la regulación de la figura de la Asistencia Financiera .40

2.2. Protección de la integridad del capital social de la compañía .41 
2.2.2 Protección de los accionistas minoritarios de la compañía .42

2.2.3 Protección de los acreedores de la compañía .44

\section{CAPÍTULO III: POSIBLES ALTERNATIVAS PARA LA REGULACIÓN DE} LA ASISTENCIA FINANCIERA EN LA LEY GENERAL DE SOCIEDADES 46

3.1 Fundamentos jurídicos y económicos en base a los cuales debe modificarse la regulación de la Asistencia Financiera en nuestra legislación societaria..46

3.2 Propuesta de modificación a la regulación de la Asistencia Financiera recogida por la actual Ley General de Sociedades

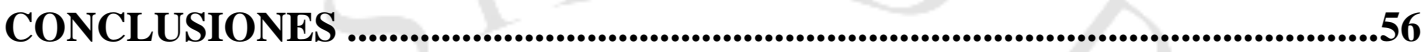

RECOMENDACIONES ....................................................................................59

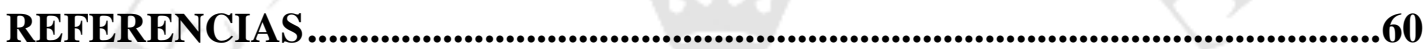




\section{INTRODUCCIÓN}

La asistencia financiera, auxilio financiero o financial assistance como se le conoce en el sistema anglosajón - y todo lo que ésta representa para el mundo de las transacciones y de las fusiones y adquisiciones - resulta una figura de estudio fascinante del derecho societario a nivel mundial.

La controversia se desató a principios del siglo XX en Inglaterra, cuando los legisladores de aquel país notaron que dicha figura se estaba llevando a la práctica con más frecuencia, junto con la adquisición por parte de una compañía de acciones de su propia emisión, denominada por el derecho societario como "autocartera".

Ante los supuestos abusos derivados de la expansión de la práctica de la figura de la asistencia financiera, comenzaron los debates para que la misma se encuentre regulada por las leyes que norman al derecho societario o al derecho de la corporaciones (company's acts), regulación que se propagó por casi toda Europa, especialmente como consecuencia de la adaptación del derecho interno de los países europeos al derecho comunitario de la Comunidad Europea ${ }^{1}$, albergando sus principales regulaciones sobre el particular en Gran Bretaña, Italia y España, siendo los sistemas italiano y español los que más se resemblan al sistema peruano.

Ahora bien, consideramos que la mayoría de la doctrina nacional e internacional no señala que la asistencia financiera no deba estar regulada, sino más bien cuestionan que se encuentre prohibida, o mucho peor, que se encuentre mal regulada, como es el caso peruano.

Por otro lado, dentro del contexto de las fusiones y adquisiciones, ésta figura, aunque un poco controvertida a nivel mundial, tiene una gran importancia y relevancia, toda vez que - y tal como procederemos a señalar en la parte pertinente del presente

\footnotetext{
${ }^{1}$ Vaquerizo (2003, p. 95) recuerda que:

Ninguno de los países europeos de nuestro entorno - a excepción de los casos ya estudiados de Gran Bretaña e Italia- disponían con anterioridad a dicha adaptación de normas relativas al fenómeno de la asistencia financiera, por lo que en este punto la incorporación de la normativa comunitaria representa una novedad que la doctrina y la jurisprudencia de tales países se apresuraron a escudriñar no sin algún grado de desconcierto.
} 
trabajo de investigación, en la gran mayoría de transacciones (por no decir en todas) en donde se busca tomar el control de una compañía objetivo, el comprador no cuenta con la totalidad del precio a pagar, por lo que necesitará de un financiamiento (de cualquier clase) para poder cerrar el negocio y "apoderarse" de la compañía (el famoso "take over").

Es aquí en donde la figura de la asistencia financiera encuentra el contexto perfecto en el cual desarrollarse toda vez que - y dependiendo de la clase de compañía objetivo que se encuentre en juego, es decir, de la industria en la cual se desempeñe, la calidad de sus activos, sus resultados financieros y, sobre todo, sus flujos de caja futuros - el comprador podrá proponerle al vendedor - actual accionista mayoritario de la compañía objetivo - que, de alguna u otra forma, la compañía objetivo termine soportando las cargas financieras de adquisición del paquete accionario que se comprará y, usualmente, esa operación se desarrollará mediante un pago diferido del precio o mediante una compra apalancada o en sus términos en inglés "leveraged buyout", operación mediante la cual, de alguna u otra forma, la misma compañía objetivo terminará cargando con la obligación de repago de la deuda tomada por el comprador para adquirir el paquete accionario que le brindaría el control de la compañía objetivo.

En ese sentido, es objetivo de la presente investigación, estudiar la figura de la asistencia financiera en general y encontrar los motivos que ha impulsado regulación en las jurisdicciones más importantes del mundo, pero sobre todo entender su regulación en nuestra Ley General de Sociedades, toda vez que esta figura ha venido siendo muy criticada desde su implementación legislativa actual debido a su redacción poco clara (por decir lo menos) y, especialmente, debido al contexto de inseguridad jurídica en la cual sitúa a la gran mayoría de operaciones de tomas de control que ocurren en nuestro país.

Asimismo, nuestra investigación buscará tener un carácter interpretativo de la norma societaria, debido que la redacción de la misma deja un camino muy ancho para su lectura, de acuerdo a lo señalado por la doctrina peruana autorizada. Por otro lado, buscaremos proponer una modificación legislativa, de igual forma a la que han venido proponiendo algunos especialistas peruanos en derecho societario.

Por último, estudiaremos los vehículos jurídicos más utilizados mediante los cuales se vienen implementado las operaciones de toma de control de paquetes 
accionarios, los cuales básicamente se centran en las compras apalancadas o leveraged buyouts y cómo éstas últimas, pese a la "estricta" regulación de nuestra Ley General de Sociedades, se vienen realizando con mayor frecuencia en nuestro país, generando cierta controversia en relación a su respaldo jurídico y posibles sanciones y contingencias legales, las cuales no pueden ser determinadas a priori debido a la oscuridad de la norma societaria que regula la asistencia financiera brindada por la sociedad objetivo a efectos de adquirir acciones de su propia emisión.

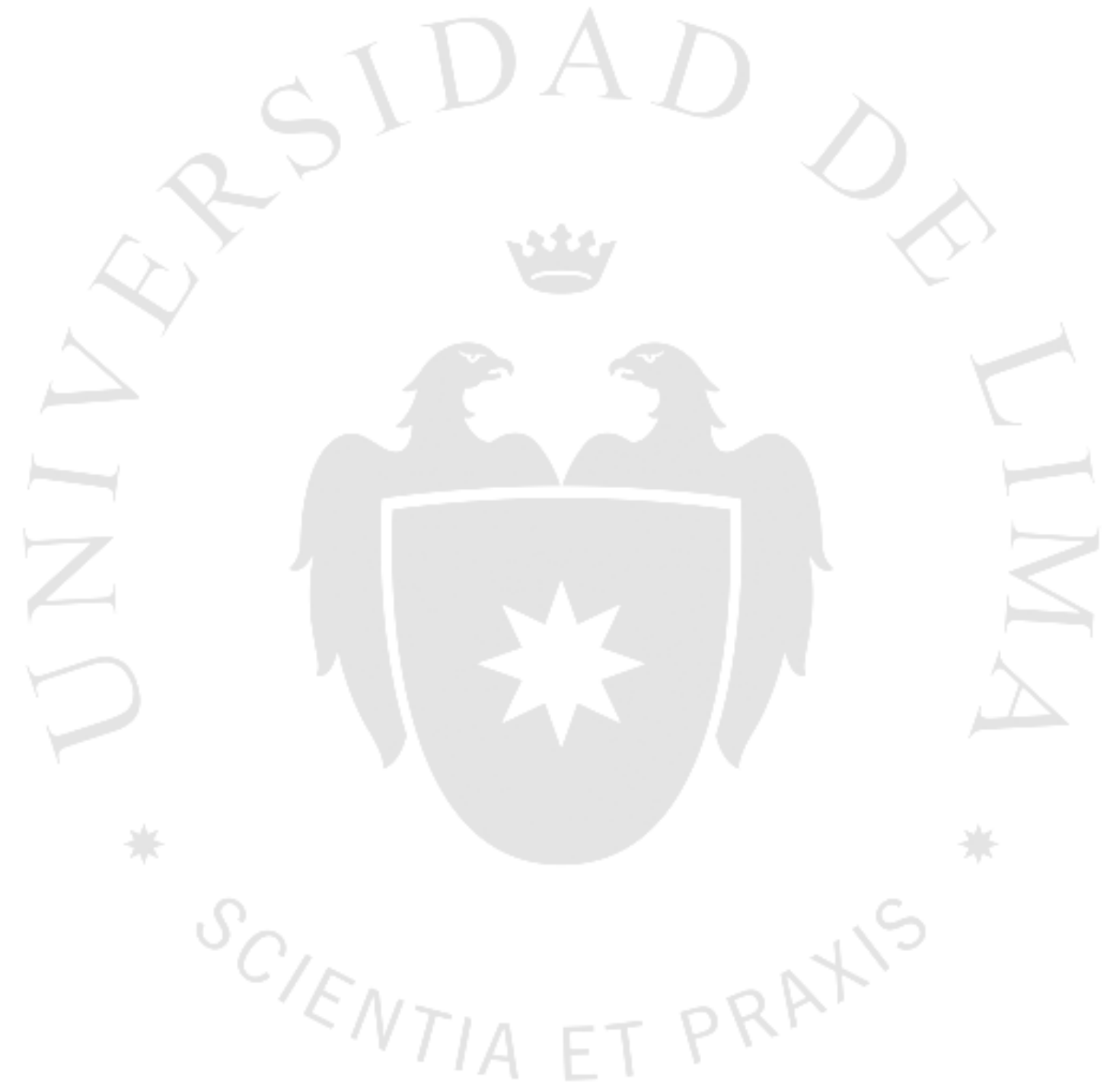




\section{CAPÍTULO I: ASPECTOS GENERALES SOBRE LA FIGURA DE LA ASISTENCIA FINANCIERA}

\subsection{Noción doctrinaria de la figura de la Asistencia Financiera}

En primer lugar, debemos comenzar señalando que el concepto de "asistencia financiera" es, en principio, uno de índole principalmente legislativo y, por ende, particular de cada legislación, es decir, dicho concepto depende de la regulación propia de cada país o comunidad, toda vez que, si bien es cierto que es posible formular una noción general de esta figura, por lo general, los alcances de la asistencia financiera siempre van a ser moldeados, a efectos de ampliarlos o restringirlos, de acuerdo a la postura de cada legislador.

De acuerdo con lo indicado en el párrafo anterior y conforme a lo señalado en el artículo $106^{\circ}$ de la Ley No. 26887, Ley General de Sociedades (9 de diciembre de 1997) (en adelante, la "Ley" o la "LGS"), la asistencia financiera está regula de acuerdo a la siguiente disposición normativa:

\section{“Artículo 106.- Préstamo con garantía de las propias acciones}

En ningún caso la sociedad puede otorgar préstamos o prestar garantías, con la garantía de sus propias acciones ni para la adquisición de éstas bajo responsabilidad del directorio."

En relación al citado artículo $106^{\circ}$ de la LGS, en la obra del profesor Elías Laroza (2015, p. 387) se señala que:

El dispositivo impide que la sociedad anónima realice operaciones de garantía o préstamos, con garantía de sus propias acciones (...). La disposición prohibitiva de la nueva Ley tiene un texto más amplio, al establecer que la sociedad no puede realizar: a) ningún préstamo, con la garantía de sus propias acciones; b) el otorgamiento de cualquier garantía por parte de la sociedad, respaldada por una garantía de sus propias acciones; y, c) cualquier préstamo o garantía por parte de la sociedad que tenga por objeto respaldar una compra de acciones emitidas por ella, con o sin garantía de estas últimas.

Como se puede apreciar, los supuestos de asistencia financiera antes señalados por el profesor Elías Laroza a la luz de su interpretación de la norma societaria han sido 
divididos en tres categorías; sin embargo, existen interpretaciones de dicha norma que nos llevan a dividirla en cuatro supuestos, como lo haremos nosotros más adelante en nuestro trabajo. Distinciones como éstas no son poco comunes al momento que se requiera analizar el artículo $106^{\circ}$ de la Ley y, en ese sentido, al momento de evaluar cuáles son los supuestos permitidos y los supuestos prohibidos y, por supuesto, si determinadas operaciones o figuras legales aplicadas en la práctica son capaces de pasar los estándares establecidos por la norma en cuestión, hay discrepancias también por quienes interpretan la norma, ya sea por fines educativos o por fines prácticos a efectos de analizar o emitir una opinión legal de una operación en particular.

Sin embargo, al igual que los profesores Guillermo Ferrero y Antonio Guarniz (2015, p. 263), somos de la consideración que los supuestos de asistencia financiera prohibidos de acuerdo a la norma peruana son los siguientes:

- La sociedad no puede otorgar préstamos para la adquisición de sus propias acciones.

- La sociedad no puede prestar garantías para la adquisición de sus propias acciones.

- La sociedad otorgue préstamos con la garantía de sus propias acciones.

- La sociedad preste garantías dando en garantía sus propias acciones.

Como se podrá apreciar, la redacción del artículo $106^{\circ}$ de la Ley, ya bastante criticado por los especialistas, abre la posibilidad de distintas interpretaciones por parte de la doctrina, debido a la complejidad y oscuridad de su redacción.

En ese sentido, de acuerdo a lo descrito en los párrafos anteriores, si bien se ha dejado en claro que la noción de asistencia financiera es puramente legislativa, a efectos de establecer una primera noción general sobre la figura, podemos concluir de forma preliminar que: la sociedad no se encuentra autorizada legalmente a otorgar préstamos a terceros para la adquisición de sus propias acciones o a otorgar garantías en contra de sus propias acciones. Sin embargo, como ya lo hemos mencionado, esta es una noción sencilla y preliminar, sobre la cual debemos ahondar más adelante. 


\subsection{Legislación internacional sobre la figura de la Asistencia Financiera}

A efectos de realizar un análisis minucioso sobre la asistencia financiera, no podemos dejar de mencionar y detallar cuáles son las principales legislaciones que la regulan y cuáles son sus alcances, ya que dicha figura existe en nuestro derecho societario gracias a lo regulado en Europa, como muchas otras figuras legales que recogidas por nuestro sistema legislativo.

\subsubsection{Regulación británica}

\section{Antecedentes legislativos}

Debemos iniciar el presente punto indicado que de acuerdo a lo establecido por López Sandoval (2004, p. 257), la figura de la asistencia financiera nació en el derecho inglés a comienzos a principios del siglo pasado y fue recogida por la Companies Act del año 1929, por motivación del señor Wilfrield Green, quien fuera el presidente de la Comisión Green (Green Committee). Esta Comisión se ocupó de generar una preocupación general por la práctica de adquisición de acciones para la toma de control de una compañía y cuyos fondos de ésta servían para pagar el préstamo tomado por los compradores para la compra de las acciones de la referida compañía, es decir, que la propia compañía era quien prestaba los fondos para la adquisición de sus propias acciones por parte de terceros.

Es gracias a esta Comisión Green antes mencionada que la Companies Act de 1929 establece prohibiciones mediante las cuales las compañías no podían prestar, de manera directa o indirecta, ayuda financiera (de cualquier clase) para la adquisición de sus propias acciones. Después de un nuevo cambio - muy criticado - el cual fue dictado a través de la Companies Act de 1948, la Comisión Jenkins (Jenkins Committee) busca analizar minuciosamente el concepto de asistencia financiera que se encontraba regulado a efectos de verificar que solo sean sancionadas las malas prácticas más no las figuras que hayan sido celebradas con buena fe (López Sandoval, 2004, p. 259).

\section{$\underline{\text { Regulación vigente }}$}


A la fecha, la legislación inglesa que rige el derecho de las corporaciones es el Companies Act del año 2006, el cual deroga el Companies Act de 1985. Esta norma relativamente nueva es la norma aplicable en el Reino Unido - es decir, en Inglaterra, Gales, Escocia y el Norte de Irlanda - y que se encuentra vigente a la fecha y que, en relación a la asistencia financiera, señala que la misma sí se encuentra permitida solo para la compra de acciones de compañías privadas pero estableciendo ciertas restricciones y limitaciones para la utilización de dicha figura.

La norma británica sobre la asistencia financiera o financial assistance incluida en las secciones 677, 678 y 679 de la Companies Act de año 2006, prohíbe las siguientes acciones:

- La asistencia financiera para la adquisición de las acciones de compañías públicas2.

- La asistencia financiera para la adquisición de acciones de la compañía privada que es la compañía matriz de una compañía pública3.

- La asistencia financiera prestada, directa o indirectamente, para la adquisición de acciones señalada en los supuestos anteriores, a efectos de reducir la responsabilidad en la cual incurrió el comprador para adquirir las acciones de la compañía pública matriz4.

Al leer las disposiciones prohibidas de asistencia financiera en la norma antes indicada, es posible concluir que estas prohibiciones solo están referidas a la asistencia financiera prestada para la adquisición de acciones en compañías públicas o que la asistencia financiera sea prestada por compañías públicas subsidiarias a efectos de adquirir acciones en su compañía matriz (holding).

Sin embargo, debemos referirnos a la sección 682 de la norma, la cual incluye las denominadas condiciones excepcionales o conditional exceptions ${ }^{5}$ referidas a la

\footnotetext{
${ }^{2}$ Section 678, assistance for acquisition of shares in public company.

${ }^{3}$ Section 679, Assistance by public company for acquisition of shares in its private holding company.

4 “(...) it is not lawful for a public company that is a subsidiary of that company to give financial assistance directly or indirectly for the purpose of reducing or discharging the liability".

5 “682Conditional exceptions

(1) Neither section 678 nor section 679 prohibits a transaction to which this section applies-

(a) if the company giving the assistance is a private company, or
} 
asistencia financiera, las cuales son supuestos en los cuales no se aplican las secciones 678 y 679 antes referidos. Entonces, la asistencia financiera estará permitida:

- Si la compañía que brinda la asistencia financiera es una compañía privada.

- Si la compañía que brinda la asistencia financiera es una compañía pública, pero ésta tiene activos netos que no se ven reducidos a causa de la asistencia brindada; o,

- En la medida que dichos activos netos se ven tan reducidos que la asistencia es proveída de las utilidades distribuibles de la compañía.

Por último, debemos mencionar que la Companies Act vigente dispone expresamente que el incumplimiento de las prohibiciones incluidas en las secciones 678 y 679 de esta norma supone la configuración de un delito (offence), sancionados con pena privativa de la libertad (imprisonment) o multa (fine).

\subsubsection{Regulación española}

\section{Aspectos generales:}

Como lo indica el autor español Alberto Vaquerizo en su obra (2003, p. 103), la primera vez que el Derecho Español incorpora la figura de la Asistencia Financiera es a través de la Ley de Sociedades Anónimas de 1989 como consecuencia de la incorporación de España como miembro de la Comunidad Europea y pese a que anteriormente la normativa española ya había establecido prohibiciones o limitaciones sobre la "autocartera" en las sociedades, tal como lo estructuró en su oportunidad el Derecho Inglés como gestor inicial de dicha regulación en Europa.

En la actualidad, la legislación societaria española vigente se encuentra recogida en el Real Decreto Legislativo 1/2010, aprobado el 2 de julio de 2010, cuerpo normativo mediante el cual se aprueba la denominada Ley de Sociedades de Capital, real decreto que deroga - entre otras normas - el Real Decreto Legislativo 1564/1989 por el cual se

(b) if the company giving the assistance is a public company and-

(i) the company has net assets that are not reduced by the giving of the assistance, or

(ii) to the extent that those assets are so reduced, the assistance is provided out of distributable profits." 
aprobó la Ley de Sociedades Anónimas (antes mencionada), norma en la cual también se regulaba la asistencia financiera para la adquisición de acciones propias en el afamado artículo $81^{\circ}$ y la Ley 2/1995, del 23 de marzo de 1955, referida a las Sociedades de Responsabilidad Limitada.

En la ley española vigente, la figura de la asistencia financiera se incluye en el artículo $150^{\circ}$, el cual reproduce casi de manera exacta el artículo $81^{6}$ de la ley anterior, solo agregando dentro del enunciado normativo la noción de "participaciones", además, de las ya mencionadas "acciones" a la prohibición de la Asistencia Financiera, tal y como lo podemos apreciar a continuación:

Artículo 150. Asistencia financiera para la adquisición de acciones propias y de participaciones o acciones de la sociedad dominante.

1. La sociedad anónima no podrá anticipar fondos, conceder préstamos, prestar garantías ni facilitar ningún tipo de asistencia financiera para la adquisición de sus acciones o de participaciones o acciones de su sociedad dominante por un tercero [cursivas añadidas]

2. La prohibición establecida en el apartado anterior no se aplicará a los negocios dirigidos a facilitar al personal de la empresa la adquisición de las acciones de la propia sociedad o de participaciones o acciones de cualquier otra sociedad perteneciente al mismo grupo.

3. La prohibición establecida en el apartado primero no se aplicará a las operaciones efectuadas por bancos y demás entidades de crédito en el ámbito de las operaciones ordinarias propias de su objeto social que se sufraguen con cargo a bienes libres de la sociedad.

\footnotetext{
${ }^{6}$ Artículo 81 del Real Decreto Legislativo 1564/1989: Asistencia financiera para la adquisición de acciones propias (hoy derogada).

La sociedad no podrá anticipar fondos, conceder préstamos, prestar garantías ni facilitar ningún tipo de asistencia financiera para la adquisición de sus acciones o de acciones de su sociedad dominante por un tercero.

2. Lo dispuesto en el apartado anterior no se aplicará a los negocios dirigidos a facilitar al personal de la empresa la adquisición de sus acciones o de acciones de una sociedad del grupo.

3. La prohibición del apartado primero no se aplicará a las operaciones efectuadas por bancos u otras entidades de crédito en el ámbito de operaciones ordinarias propias de su objeto social que se sufraguen con cargo a bienes libres de la sociedad.

Esta deberá establecer en el pasivo del balance una reserva equivalente al importe de los créditos anotados en el activo.
} 
En el patrimonio neto del balance, la sociedad deberá establecer una reserva equivalente al importe de los créditos anotados en el activo.

De la lectura de la norma española que se refiere a la figura de la asistencia financiera, es válido señalar que el legislador establece supuestos prohibitivos específicos y un supuesto general que se entendería como una suerte de cajón de sastre para las operaciones que no encajan dentro de las figuras jurídicas de préstamos o garantías, pero involucran actos que faciliten financieramente la adquisición de acciones (o participaciones) de propia emisión de la compañía objetivo.

Básicamente en el artículo $150^{\circ}$ incluye los siguientes supuestos prohibitivos:

- La sociedad no podrá (i) anticipar fondos, (ii) conceder préstamos, (iii) prestar garantías, ni (iv) facilitar ningún tipo de asistencia financiera para la adquisición de sus acciones o de participaciones por un tercero.

- La sociedad no podrá (i) anticipar fondos, (ii) conceder préstamos, (iii) prestar garantías, ni (iv) facilitar ningún tipo de asistencia financiera para la adquisición de acciones o de participaciones de su sociedad dominante por un tercero.

Al analizar la norma española, podemos notar que el legislador español ha considerado que la asistencia financiera para la adquisición de las acciones y de participaciones de la sociedad o de la sociedad dominante o matriz, es tan relevante como la asistencia financiera para la adquisición de las acciones propias de la sociedad. Este supuesto no está incluido en la regulación peruana, como se puede notar de la redacción de nuestro artículo $106^{\circ}$ de la LGS.

Como ya hemos mencionado, entre la norma española anterior del año 1989 y la actual del año 2010, solo se establece una solo diferencia, que es la incorporación del concepto de "participaciones", por lo que, en líneas generales y para efectos interpretativos de la norma española, aún son aplicables las observaciones realizadas por la doctrina de este país sobre la redacción del artículo sobre la asistencia financiera que estaba considerado en la norma española de 1989.

Para Vaquerizo (2003) es necesaria la utilización de varios recursos interpretativos para poder leer la norma, señalando de esta manera lo siguiente:

Debe tenerse en cuenta, no obstante, que en este momento - y mediante la aludida descripción- se pretende obtener únicamente una delimitación en cierto modo preliminar del ámbito de aplicación de la prohibición, dado que, si bien la correcta determinación 
del supuesto de hecho normativo constituye una parte esencial de los materiales para la interpretación jurídica (aquella que se encuentra más apegada a la literalidad del precepto), lo cierto es que la descripción típica de los elementos integrantes de la conducta constitutiva del citado supuesto de hecho no agota tales materiales, siendo necesario acudir a otros recursos interpretativos de orden teológico o sistemático para completar el conocimiento de la concreta realidad material a la que la norma está llamada a aplicarse [cursivas añadidas]. Ello es así muy especialmente en relación con el tipo de operación que constituye el objeto de nuestro estudio, habida cuenta del carácter genérico e impreciso con el que se contemplan por el propio enunciado legal los actos susceptibles de integra aquella conducta (p. 116).

Como se puede apreciar, para la doctrina española también consideró (y sigue considerando) que una norma prohibitiva como ésta debe ser interpretada con la ayuda de varios recursos, puesto que, al ser limitativa de derechos, una sola y única forma de interpretación restringiría de manera injusta las operaciones de las compañías. A esta opinión, debemos agregarle que, bajo nuestra perspectiva, norma española ha sido redactada de una forma mucho más clara y ordenada, no pudiendo compararse con el caso peruano y la redacción del artículo $106^{\circ}$ de la Ley, el cual deja una panorama difuso y lleno de incertidumbre para las sociedades y sus representantes.

En su obra, Vaquerizo (2003) ha estructurado de manera muy ordenada el método de análisis de la figura de la asistencia financiera en la legislación española, tratando de dejar muy claro que una norma como ésta, en España o en cualquier jurisdicción, debe ser tratada con mucho cuidado, ya que se están conjugando los intereses de la sociedad, de los accionistas, de los administradores de la sociedad, de los acreedores de la sociedad y de los terceros que se encuentren interesados en adquirir una participación en la sociedad objetivo en cuestión, ya sea que dicha participación sea importante o no dentro de la composición accionaria de la compañía.

\section{Características normativas relevantes de la legislación española:}

No queremos cerrar el estudio de la regulación española sobre la asistencia financiera sin destacar de manera muy breve los aspectos relevantes de la norma citada:

a) En primer lugar, el legislador español es directo y ha catalogado a la asistencia financiera como tal, indicando expresamente (como se puede apreciar en la norma antes citada) “Asistencia financiera para la adquisición de acciones propias”. 
En nuestra opinión, éste es un punto importante desde el punto de vista formal y material, ya que, desde la primera vista, el lector entiende y capta cuál es la figura del derecho que se está regulando y que la regulación española ha considerado relevante regularla, a pesar que sabemos que fue un mandamiento imperativo del país que deseaba formar parte de la Comunidad Europa.

b) En segundo lugar y como ya lo habíamos mencionado en los párrafos anteriores, la norma está compuesta por dos tipos de prohibiciones: tres prohibiciones expresas y una prohibición general.

Las prohibiciones expresas son las de no anticipar fondos, conceder préstamos ni prestar garantías; mientras que la prohibición general consiste en la no prestación de asistencia financiera en general por parte de la sociedad para la adquisición de las acciones de su propia emisión. Este cajón de sastre es importantísimo, ya que es necesario entender qué se entiende por asistencia financiera para comprender que actos se encuentran prohibidos por la cláusula general.

Bajo la interpretación de Vaquerizo (2003), la inclusión de la una cláusula general en la norma implica un seguimiento a la pauta marcada por el Derecho Británico, resaltando además como los ordenamientos de la Comunidad Europea y sus respectivas doctrinas entienden que, aun así, no se incluya una cláusula general como la que vemos en el caso español, se debería aplicar la argumentación finalista de la norma.

Sobre el particular, Vaquerizo (2003) señala lo siguiente:

(...) en todos los ordenamientos donde la norma se incorpora sin una mención expresa de la cláusula general de asistencia, la doctrina- siguiendo una argumentación finalista- se muestra mayoritariamente partidaria de entender la existencia implícita de dicha cláusula, de manera que queden comprendidos por la prohibición no solamente los negocios específicos que la norma menciona sino también aquellos otros que respondan de facto a su misma ratio económica [cursivas añadidas] (p.153).

Ésta interpretación puede resultar un poco controvertida, sobre todo teniendo en consideración que en nuestro sistema peruano las normas que restringen derechos (como lo es claramente la regulada por el artículo $106^{\circ}$ de la Ley) deberían, según varios autores, ser interpretadas bajo el principio de literalidad y no de fraude a la ley, el cual implicaría la utilización de la analogía; por lo tanto, todos los supuestos o conductas que NO 


\section{forman parte del supuesto de hecho legal, NO deberían de ser interpretados como}

ilegales.

En todo caso, el legislador español fue más astuto - por decirlo de alguna manera - e incluyó una cláusula general explícita que no deje espacio alguno para que los abogados transaccionales (como nosotros) que buscan aplicar figuras y estructuras legales y financieras sofisticadas o complejas que no encajen exactamente dentro del supuesto de hecho típico y, por lo tanto, no sean objeto de cuestionamiento legal o ético o que, en todo caso, se encuentren en una zona gris que no se les permita ser tachados abiertamente de ilegales.

c) Continuando con los aspectos relevantes de la norma española materia del presente subcapítulo, debemos destacar que el artículo $150^{\circ}$ expresamente señala dos casos concretos que $\underline{\text { NO }}$ deben ser considerados como supuestos prohibidos: (i) las adquisiciones de acciones de la sociedad y de otra sociedad del grupo por parte de los trabajadores de la primera y (ii) las operaciones efectuadas por los bancos u otras entidades de crédito dentro de las operaciones ordinarias de su objeto social, cumpliendo claro con la obligación que las mismas se sufraguen con cargo a bienes libres de la sociedad y se establezcan como pasivo en el balance equivalente al importe de los créditos anotados en el activo.

Personalmente, nos parece que dichas precisiones en la norma española son adecuadas y oportunas y buscan dejar en claro que operaciones no son consideradas como asistencia financiera prohibida.

En relación al primer caso, es claro que el legislador ha buscado fomentar la adquisición de las acciones y participaciones de la sociedad o de una sociedad del grupo por parte de los trabajadores de la primera, blindando de esta manera cualquier tipo de negocios que involucren la prestación de facilidades a los trabajadores para lograr dicho objetivo.

Asimismo, el legislador español ha excluido a los bancos u otras entidades de crédito dentro de las operaciones ordinarias de éstos, claro cumpliendo con las condiciones que establece la norma. 


\subsubsection{Regulación italiana}

En el caso de la legislación italiana sobre la asistencia financiera, debemos resaltar que la misma se incluye en el Código Civil italiano aprobado por Decreto Real No.262 del 16 de marzo de 1942 y cuyo artículo actual sobre la regulación de la figura de asistencia financiera fue modificado por el Decreto Legislativo emitido el 4 de agosto de 2008, es decir, que se trata de una regulación relativamente nueva como en el caso español antes estudiado.

El artículo $2358^{\circ 7}$ del Código Civil italiano en la cual se regula la asistencia financiera señala una serie de requisitos para el otorgamiento de préstamos y constitución de garantías, se deben cumplir con las condiciones que se detallan en dicho artículo.

\footnotetext{
7 2358: Altre operazioni sulle proprie azioni
}

La societa' non puo', direttamente o indirettamente, accordare prestiti, ne' fornire garanzie per l'acquisto o la sottoscrizione delle proprie azioni, se non alle condizioni previste dal presente articolo.

Tali operazioni sono preventivamente autorizzate dall'assemblea straordinaria.

Gli amministratori della societa' predispongono una relazione che illustri, sotto il profilo giuridico ed economico, l'operazione, descrivendone le condizioni, evidenziando le ragioni e gli obiettivi imprenditoriali che la giustificano, lo specifico interesse che l'operazione presenta per la societa', i rischi che essa comporta per la liquidita' e la solvibilita' della societa' ed indicando il prezzo al quale il terzo acquisira' le azioni. Nella relazione gli amministratori attestano altresi' che l'operazione ha luogo a condizioni di mercato, in particolare per quanto riguarda le garanzie prestate e il tasso di interesse praticato per il rimborso del finanziamento, e che il merito di credito della controparte e' stato debitamente valutato. La relazione e' depositata presso la sede della societa' durante i trenta giorni che precedono l'assemblea. Il verbale dell'assemblea, corredato dalla relazione degli amministratori, $e^{\prime}$ depositato entro trenta giorni per l'iscrizione nel registro delle imprese.

In deroga all'articolo 2357-ter, quando le somme o le garanzie fornite ai sensi del presente articolo sono utilizzate per l'acquisto di azioni detenute dalla societa' ai sensi dell'articolo 2357 e

2357-bis l'assemblea straordinaria autorizza gli amministratori a disporre di tali azioni con la delibera di cui al secondo comma. Il

prezzo di acquisto delle azioni e' determinato secondo i criteri di cui all'articolo 2437-ter, secondo comma. Nel caso di azioni negoziate in un mercato regolamentato il prezzo di acquisto é pari almeno al prezzo medio ponderato al quale le azioni sono state negoziate nei sei mesi che precedono la pubblicazione dell'avviso di convocazione dell'assemblea.

Qualora la societa' accordi prestiti o fornisca garanzie per l'acquisto o la sottoscrizione delle azioni proprie a singoli amministratori della societa' o della controllante o alla stessa controllante ovvero a terzi che agiscono in nome proprio e per conto dei predetti soggetti, la relazione di cui al terzo comma attesta altresi' che l'operazione realizza al meglio l'interesse della societa'.

L'importo complessivo delle somme impiegate e delle garanzie fornite ai sensi del presente articolo non puo' eccedere il limite degli utili distribuibili e delle riserve disponibili risultanti dall'ultimo bilancio regolarmente approvato, tenuto conto anche dell'eventuale acquisto di proprie azioni ai sensi dell'articolo

2357. Una riserva indisponibile pari all'importo complessivo delle somme impiegate e delle garanzie fornite e' iscritta al passivo del bilancio.

La societa' non puo', neppure per tramite di societa' fiduciaria, o per interposta persona, accettare azioni proprie in garanzia.

Salvo quanto previsto dal comma sesto, le disposizioni del presente articolo non si applicano alle operazioni effettuate per favorire l'acquisto di azioni da parte di dipendenti della societa' o di quelli di societa' controllanti o controllate.

Resta salvo quanto previsto dagli articoli 2391-bis e 2501-bis. 
Los requisitos son los siguientes:

- Que la operación sea aprobada por asamblea extraordinaria.

- Para tales efectos, la administración debe autorizar la operación mediante la elaboración de informe con todas las implicancias económicas y jurídicas, explicando las razones de la operación, las condiciones, el interés de la sociedad en celebrarla, los riesgos de liquidez y de solvencia, el detalle del precio y de las condiciones de mercado, así como las condiciones financieras y las garantías que se otorgan a favor de la Sociedad y el detalle de la evaluación crediticia del beneficiario del préstamo o garantía.

- Asimismo, el artículo también se coloca en el supuesto que la sociedad cotice sus acciones en la bolsa a efectos de determinar el precio de las mismas.

- Por otro lado, regula la adquisición de las acciones por parte de los directores.

- También se establece una limitación monetaria que se encuentra restringida por los beneficios distribuibles y las reservas disponibles de la sociedad.

- Prohíbe de igual manera la aceptación de las acciones de su propia emisión como garantía.

- Y, por último, promueve la adquisición de acciones por parte de los trabajadores de la sociedad o de la sociedad controladora y controlada, bajo algunas condiciones.

- Como se puede apreciar, el Código Civil italiano ha sido muy minucioso en regular esa figura, y su larga extensión abarca el cumplimiento de una serie de requisitos y de presupuestos bastante rigurosos a efectos de salvaguardar los derechos y la estabilidad de la sociedad y de sus accionistas. En nuestra opinión, este artículo debe ser una guía para una reforma legislativa peruana.

\subsection{Regulación de la figura de la Asistencia Financiera de acuerdo a la Ley} General de Sociedades Peruana 


\subsubsection{Análisis del artículo $106^{\circ}$ de la Ley General de Sociedades Peruana:}

\subsubsection{Análisis doctrinario sobre la Asistencia Financiera:}

\section{A) La posición doctrinaria de Enrique Elías Laroza:}

Como ya lo habíamos señalado en la primera parte del presente trabajo de investigación, la redacción del artículo $106^{\circ}$ es poco clara - por decir lo menos- y ha obligado a que la interpretación del mismo tenga una base fundamentalmente doctrinaria, comenzando por supuesto por la de nuestro maestro Enrique Elías Laroza contenida en su libro "Derecho Societario Peruano".

De esta manera, Elías Laroza (2015) señala que en la Ley se establece una premisa más amplia que en la ley de sociedades anterior, y que de su lectura se puede interpretar que:

(...) la sociedad no puede realizar: a) ningún préstamo, con la garantía de sus propias acciones; b) el otorgamiento de cualquier garantía por parte de la sociedad, respaldada por una garantía de sus propias acciones: y c) cualquier préstamo o garantía por parte de la sociedad que tenga por objeto respaldar una compra de acciones emitidas por ella, con o sin garantía de estas últimas (p. 387).

Por otro lado, es el propio maestro Enrique Elías (2015) quien esboza varias justificaciones para respaldar su regulación en la Ley. A continuación, presentamos las que consideramos más relevantes para efectos del presente trabajo:

\section{a) Devolución indebida de aportes del accionista:}

(...) Realizar una operación de préstamo o de garantiza, con la garantía de sus propias acciones, representa para la sociedad anónima una forma indirecta de facilitar recursos líquidos al accionista o sea, en otras palabras, una forma de reducción de capital encubierta (al igual que ciertas adquisiciones de acciones de propia emisión, que según el artículo 104 de la Ley se hacen solamente con cargo a utilidades y reservas libres y no con cargo al capital) (...) (p.388).

A lo que se refiere el profesor Enrique Elías es que, si el deudor de la sociedad a quien se le ha aceptado como respaldo del préstamo otorgado por ésta las acciones de las 
cuales es titular en la sociedad, incumpliese con el pago de la deuda, la sociedad tendría que ejecutar la garantía adjudicándose las acciones de su propia emisión, lo que indirectamente significaría que se le estarían devolviendo los aportes al accionista que no cumplió con devolver el préstamo otorgado por la sociedad.

\section{b) Empoderamiento del grupo accionario dominante de la Sociedad:}

(...) El establecimiento de garantías en favor de la sociedad sobre las acciones de propia emisión puede dar lugar a una fácil forma de abuso por parte de los administradores, consistente en utilizar fondos o el crédito de la sociedad para otorgar préstamos a accionistas necesitados de liquidez (o para que la sociedad garantice prestamos de terceros a esos accionistas), a cambio no solamente de lograr el préstamo, sino también para conseguir que el accionista ceda sus derechos de voto a favor de los socios que controlan el directorio de la sociedad. De esta manera se llega indirectamente a una situación que es precisamente la del fraude que pretenden enviare el último acápite del articulo 104 y el artículo 105 de la LGS: o sea que mediante la utilización de los fondos y del crédito de la sociedad (que son de todos), se logre aumentar el caudal de votos comprometidos a favor solo de un grupo dominante (pp. 389-390).

Sobre este punto, debemos anotar que si los administradores de la sociedad otorgan préstamos a favor de los accionistas que claramente no pueden obtenerlos por si solos por terceros ajenos a la sociedad, estos accionistas pueden estar "vendiendo" sus votos en la junta a cambio de liquidez y, por supuesto, estos votos serían para apoyar al grupo accionario más poderoso y significativo de la sociedad y grupo que además ha nombrado (de acuerdo a lo estipulado a la Ley y al estatuto) a la mayoría de los miembros del directorio de la sociedad, apoyando de esta manera a las causas más convenientes para el grupo de accionistas con más poder en la sociedad, quien, a este paso se volverá cada vez más poderoso.

Asimismo, y de acuerdo a lo señalado en la obra del profesor Enrique Elías (2015, p. 390), esta posición se ve reforzada por el hecho que, deja mucho que pensar sobre la real situación de la sociedad en el mercado, que un accionista no pueda recibir financiamientos por parte de terceros otorgando como garantía las acciones de la sociedad de las cuales es titular. Por lo tanto, si es el directorio de la propia sociedad quien decide otorgarle el préstamo y acepta las acciones (de su propia emisión) como 
garantía a cambio de su "voto favorecedor" en las juntas de accionistas, esto puede implicar que una administración inadecuada siga siendo la encargada de la sociedad y que las necesidades personales de los accionistas y de los administradores sean valorados por encima del interés y buen desarrollo del objeto social de la compañía.

\section{d) Una violación al principio de imparcialidad por parte de los administradores:}

(...) Al peligro señalado en el acápite anterior debe sumarse otro, también consignado por la doctrina: la utilización de los recursos sociales cuando los administradores están interesados en incrementar derechos de voto a su favor rompe el principio de imparcialidad que debe guiar a los administradores en sus relaciones con todos los accionistas de la sociedad. Al fin de cuentas, el interés del grupo dominante acaba privilegiando a los socios más necesitados, que normalmente son los menos solventes (p. 390).

En la misma línea de pensamiento que la plasmada en el punto anterior, la obra del profesor Enrique Elías (2015) nos habla sobre la violación al principio de imparcialidad que deben respetar los administradores al momento de atender y valorar las necesidades de los accionistas de la sociedad. Como sabemos, en la gran mayoría de los casos, dentro de la composición accionaria de una compañía, casi siempre cada accionista o cada grupo de accionistas va a procurar que la sociedad sea dirigida de determinada manera, pues, si bien las sociedades tienen un estatuto y un objeto social que las encamina, al tratarse de ficciones jurídicas que al final albergan intereses humanos, cada accionista o grupos de accionistas van a querer hacer predominar sus intereses.

En ese sentido, los órganos administrativos de la sociedad son los que deben procurar lograr el éxito de la sociedad como un "todo", que, al final beneficiará a todos los accionistas y no solo a un grupo de ellos. Por lo tanto, a efectos de aterrizar con la idea, el hecho que los directores le faciliten liquidez a algunos accionistas aceptando a cambio las acciones de la sociedad como garantía y todo lo que ello implica (mencionado ya líneas arriba) pone en duda que el directorio actúe procurando el bien social y no el bien personal de los accionistas o del grupo mayoritario de accionistas, conducta que se encuentra restringida por la Ley.

Asimismo, el profesor Elías Laroza (2015, p. 392) hace una muy breve mención sobre la prohibición del otorgamiento de préstamos o garantías, con o sin garantía de 
acciones, para procurar la adquisición de acciones de emisión de la propia compañía, indicando que esta prohibición expresa busca evitar la que “(...) la sociedad pueda destinar recursos o convertirse en garante para lograr la suscripción y pago de sus propias acciones."

En nuestra opinión, la mayor parte de la interpretación del artículo $106^{\circ}$ hecha por el profesor Enrique Elías Laroza se concentra en motivar que la razón de ser de la norma radica en evitar (i) el fraude a otras disposiciones legales que se encuentran contenidas en la LGS, específicamente en los artículos $104^{\circ}$ - referido a la adquisición por la sociedad de sus propias acciones y $105^{\circ}$ - referido al control indirecto de acciones así como (ii) el conflicto de intereses y la responsabilidad del directorio - referidos en los artículos $177^{\circ}$ y $180^{\circ}$ de la misma Ley.

Hacemos esta afirmación puesto que, como consecuencia de nuestra investigación, hemos notado que otros autores - tanto nacionales como internacionales han justificado la existencia de la norma en otros motivos y, asimismo, han concentrado la mayor parte de sus interpretaciones en el otorgamiento de préstamos y de garantías por parte de la sociedad para la adquisición de acciones de su propia emisión.

B) La posición doctrinaria de los profesores Eduardo López Sandoval y de Guillermo Ferrero y Antonio Guarniz:

En concordancia con lo manifestado anteriormente, en nuestra doctrina nacional, hemos podido encontrar que, por ejemplo, Eduardo López Sandoval (2004, p. 268), al momento de analizar la finalidad principal del artículo $106^{\circ}$ de la Ley que regula la asistencia financiera en nuestra legislación, llega a concluir que la misma radica en que la sociedad está prohibida de otorgar préstamos y garantías para lograr la adquisición de acciones de su propia emisión. Es decir, que, al igual que la doctrina española anteriormente abordada en el presente trabajo y a efectos dirigir su propia investigación, este autor también centra la explicación de la figura de la asistencia financiera en el uso de liquidez (préstamos) y respaldo (garantías) para lograr adquirir acciones de la sociedad que le brinda al tercero dichas facilidades.

Sin embargo, este autor (López Sandoval, 2004, p. 269) también cumple con resaltar que a luz de la lectura de la norma del artículo $106^{\circ}$, la doctrina nacional se 
encuentra divida al momento, por ejemplo, de determinar en qué momento se debe producir la asistencia financiera, si antes o después de la adquisición de las acciones.

Para tales efectos, llega a la conclusión, junto con el resto de la doctrina versada en el tema, que independientemente al momento en el cual se efectúa la asistencia financiera, lo relevante es analizar la intencionalidad de la operación, es decir, si el acto de "asistir financieramente" sirvió, al fin y al cabo, para lograr la adquisición de las acciones.

Sin embargo y sin perjuicio de lo antes señalado, nos gustaría mencionar la opinión de una de las autoras españolas a las que cita Eduardo López Sandoval a efectos que mostrar cómo, la interpretación extensiva de la norma que recoge a la asistencia financiera, tanto en España como en el Perú, puede ser aceptada si es que la amparamos en el fraude a la ley, es decir, en el ánimo de burlar una norma imperativa realizando el acto cuya finalidad es la que prohíbe dicha norma mediante la utilización de una mecanismo alternativo o una norma de cobertura.

Para tales efectos, López Sandoval (2004), citando a Beatriz Satrústegui (2001, p. 435), manifiesta lo siguiente:

Es perfectamente defendible que ni el préstamo posterior ni el dado anteriormente con otra finalidad están cubiertos por la letra del articulo 81.1 LSA, y no estándolo, y evitando interpretaciones extensivas de la norma prohibitiva, solo podrán entenderse contenidos o no en la prohibición en la medida en la que pueda considerarse que constituyen un fraude a la ley [cursivas añadidas] (p.269).

Por otro lado, al igual que el profesor Elías Laroza (2015) y nuestra doctrina más reciente que ha opinado sobre el presente tema, como lo son los abogados López (2004) y Ferrero y Guarniz (2015) así como la doctrina española, presentan las justificaciones a la regulación de la asistencia financiera que se basan principalmente en la (i) protección del capital social; (ii) la protección de los accionistas minoritarios; (iii) la protección de los acreedores de la compañía y (iv) la defensa de los intereses de la sociedad frente a los intereses de terceros (como lo son los accionistas y los administradores.

Estas justificaciones serán expuestas con mayor amplitud en los próximos capítulos. 


\subsubsection{Análisis legal sobre los supuestos de Asistencia Financiera Prohibida}

A efectos de comenzar a desmenuzar el artículo $106^{\circ}$ de la LGS, cumplimos con citarlo nuevamente:

\section{Artículo $106^{\circ}$.- Préstamos con garantía de las propias acciones \\ En ningún caso, la sociedad puede otorgar préstamos o prestar garantías, con la garantía de sus propias acciones ni para la adquisición de éstas bajo responsabilidad del directorio.}

Como vemos, la redacción no nos ayuda mucho, al contrario, nos provoca confusión, como lo hizo en reiteradas ocasiones al momento de tratar de entender la norma y sus alcances; tanto es así que, sin la ayuda de la doctrina nacional y extranjera- especialmente de la española - de la cual heredamos la regulación sobre la asistencia financiera (solo en el alma, más no en forma), no hubiéramos entendido con claridad las razones detrás de semejante artículo.

En nuestra opinión, la norma contiene las siguientes prohibiciones:

La Sociedad NO puede:

- Otorgar préstamos para la adquisición de acciones de su propia emisión.

- Otorgar garantías para la adquisición de acciones de su propia emisión.

- Otorgar préstamos con la garantía de sus propias acciones.

- Otorgar garantías con la garantía de sus propias acciones.

Como se puede apreciar, la regulación de la asistencia financiera prohibida tiene dos horizontes:

a) El primero es evitar que los fondos y la liquidez de la sociedad sean utilizados por terceros - llámense los accionistas y/o los administradores de la sociedad o personas (naturales o jurídicas) externas a ésta - para adquirir acciones de propia emisión de la sociedad; y,

b) El segundo es que la sociedad respalde préstamos -otorgados por la misma sociedad o por terceros - aceptando acciones de su propia emisión como garantía. 
Ahora bien, tal y como lo desarrollaremos en el próximo capítulo, existen teorías no solo para regular la asistencia financiera, sino para prohibirla, pero todas ellas tienen un núcleo en común: y es procurar la aplicación de principios de un buen gobierno corporativo dentro de la sociedad y evitar conflictos de intereses entre los accionistas de la sociedad, los administradores, los acreedores y terceros ajenos a la sociedad, terceros que tal vez tengan interés en formar parte de ella.

Sin embargo y pese a que la ratio legis de la existencia del artículo $106^{\circ}$ de la Ley no dejan de ser teorías sumamente importantes y válidas, eso no deja de lado el hecho que la figura no se encuentra regulada de la mejor manera o, por lo menos, de una manera inteligible.

A continuación, procederemos a analizar cada premisa de asistencia financiera prohibida que hemos encontrado dentro de la norma.

\section{A.1) Sobre el otorgamiento de préstamos para la adquisición de acciones de propia emisión de la sociedad:}

Ésta primera prohibición se encuentra contenida en las legislaciones que regulan y restringen la asistencia financiera. Desde los antecedentes ingleses que hemos narrado y mencionado a lo largo del presente trabajo, los legisladores consideran injusto que la sociedad literalmente financie al tercero que quiere adquirir acciones de ésta para convertirse en accionista y, la impresión se agrava aún más cuando el préstamo a servido para que se convierta en el accionista mayoritario de la sociedad y así logre tomar el control de la compañía. Claro, en nuestra opinión resulta perfectamente comprensible el sentido de "injusticia" que genera este comportamiento.

Sin embargo, ya no estamos en a principios del siglo $\mathrm{XX}$ y, si bien debemos procurar que la regulación sea igualitaria para todos y preserve los derechos de todos por igual, no es menos cierto que, a veces, la norma debe hacer prevalecer el beneficio económico y eficiente de las operaciones para la sociedad.

Por ejemplo, de las fusiones y adquisiciones, los que se busca hacer prevalecer es la distribución eficiente de los recursos de una sociedad; es decir, que las compañías sean manejadas por los accionistas y los administradores más capaces y eficientes, quienes van a lograr - o al menos intentar ya que tienen la experiencia para ello - que la sociedad dé frutos maximizando sus activos y/o aumentando sus flujos o haga crecer su 
reputación en el mercado y, que finalmente, una vez que haya superado su punto de equilibrio, logre distribuir las utilidades a los accionistas (Ferrero y Guarniz, 2015).

Bajo la misma línea de pensamiento, nos preguntamos ¿qué tendrá de malo que la sociedad otorgue préstamos para que terceros adquieran sus propias acciones? En nuestra opinión, no tiene nada de malo, siempre y cuando se establezca y respete el marco jurídico que proteja, por sobre todas las clases de intereses, el interés de la sociedad como ente independiente y una ficción del derecho creada para existir de forma separada de sus accionistas.

En ese sentido, tal vez no sea relevante el sentido de falta de justicia que la sociedad (que responde a la expectativa de los accionistas y de los acreedores de la misma) sino que la asistencia financiera brindada en forma de préstamos, como es el presente caso, sea concedida bajo condiciones de mercado y sin otorgar mayores ventajas que el hecho que la sociedad mire al tercero prestatario como sujeto de crédito, a diferencia de otros prestamistas que se encuentran en el mercado.

Para tales efectos, los profesores Ferrero y Guarniz (2015, p. 263) nos recuerdan que los directores de la sociedad pueden celebrar contratos con la sociedad siempre que se traten de operaciones que normalmente celebre con terceros (otros) y que los haga bajo condiciones de mercado, conforme a lo estipulado en el artículo $179^{8}$ de la Ley.

\footnotetext{
${ }^{8}$ Artículo 179.- Contratos, créditos, préstamos o garantías

El director sólo puede celebrar con la sociedad contratos que versen sobre aquellas operaciones que normalmente realice la sociedad con terceros y siempre que se concerten en las condiciones del mercado. La sociedad sólo puede conceder crédito o préstamos a los directores u otorgar garantías a su favor cuando se trate de aquellas operaciones que normalmente celebre con terceros.
}

Los contratos, créditos, préstamos o garantías que no reúnan los requisitos del párrafo anterior podrán ser celebrados u otorgados con el acuerdo previo del directorio, tomado con el voto de al menos dos tercios de sus miembros.

Lo dispuesto en los párrafos anteriores es aplicable tratándose de directores de empresas vinculadas y de los cónyuges, descendientes, ascendientes y parientes dentro del tercer grado de consanguinidad o segundo de afinidad de los directores de la sociedad y de los directores de empresas vinculadas.

Los directores son solidariamente responsables ante la sociedad y los terceros acreedores por los contratos, créditos, préstamos o garantías celebrados u otorgados con infracción de lo establecido en este artículo. 
Entonces, nos preguntamos lo siguiente: Si los directores tienen dicha posibilidad, respetando claro las condiciones detalladas en el artículo antes citado, ¿por qué no lo pueden tener los mismos accionistas de la sociedad, por ejemplo, si éstos desean adquirir más acciones de está e incrementar su porcentaje accionario?

Creemos que la regulación adecuada de la asistencia financiera es el vehículo perfecto para que balancear los derechos y obligaciones de los personajes que giran al alrededor de la sociedad. ¿Por qué no permitir el otorgamiento de préstamos bajo las condiciones normativas adecuadas que generen que la sociedad se comporte de una manera más eficiente y que equilibren los intereses de todos los protagonistas de la vida de la compañía?

Asimismo, es importante mencionar que hay empresas cuyo core business es el otorgamiento de mutuos dentro de sus actividades ordinarias, ¿qué sucede en estos casos? ¿También debemos considerarlos como asistencia financiera prohibida?

Como lo vimos en el pasaje en el cual reseñamos la legislación española de la asistencia financiera ${ }^{9}$, el legislador de este país excluye expresamente, por ejemplo, a los bancos y otras entidades de crédito que dentro del campo de sus actividades ordinarias y con cargo al cumplimento de ciertas condiciones contables, anticipen fondos; concedan préstamos; presten garantías y faciliten algún tipo de asistencia financiera. Tal vez a nuestro legislador le corresponda detallar asimismo las excepciones a sus prohibiciones a la asistencia financiera, teniendo en consideración que existen sociedades - no solo bancos o entidades financieras - que tienen como objeto social el otorgamiento de mutuos y créditos.

Ahora bien, debido a que literalmente "la sociedad está prohibida a otorgar préstamos para la adquisición de sus propias acciones", que sucedería si la sociedad le otorga un préstamo a un tercero y este tercero le presta los fondos a otro tercero para que adquiera más acciones de la compañía. Bajo una interpretación literal ${ }^{10}$, la sociedad no

\footnotetext{
${ }^{9}$ Véase el punto 1.2.2 del capítulo primero del presente trabajo.

${ }^{10}$ También podría tomarse en consideración el ejemplo que los profesores Ferrero y Guarniz (2015) señalan en su artículo: "Consideremos como ejemplo una situación típica de compra apalancada: una persona asume una deuda para comprar acciones. Luego de haberlas adquirido, y considerando que con esa adquisición se convirtió en el accionista mayoritario de la empresa con noventa por ciento de las acciones, genera que la empresa adopte los acuerdos necesarios para que ésta lo sustituya como obligado (novación subjetiva) en la deuda en la que él incurrió originalmente para comprar acciones.

Si la revisamos con cuidado, la norma no prohíbe literalmente que la sociedad asuma la deuda de un tercero (inclusive en el contexto de la compra de las propias acciones). Lo que prohíbe es que la sociedad
} 
estaría incumpliendo con la prohibición de la norma, pues no se cumple el supuesto de hecho de manera exacta, sin embargo, si podemos notar que se está vulnerando el espíritu y la finalidad de la norma si utilizamos una interpretación extensiva de la norma vía “fraude a la ley" o "abuso del derecho".

En todo caso e independientemente del método interpretativo que utilicemos, $\underline{\text { lo }}$ cierto es que el hecho de que tengamos una norma que recoja supuestos prohibitivos que se encuentran redactados de una manera poco clara, lo único que causa es inseguridad jurídica y el planeamiento de estructuras legales complejas para tratar de no caer en los supuestos de hecho prohibitivos.

\section{A.2) Sobre el otorgamiento de garantías para la adquisición de acciones de propia emisión:}

Asimismo, el artículo $106^{\circ}$ de la Ley nos prohíbe que la sociedad otorgue garantías para respaldar la adquisición de acciones de su propia emisión. Claro, como bien lo indicábamos en páginas anteriores, el principal miedo de detrás de una prohibición de este tipo, es que, ante el incumplimiento de la obligación por parte del deudor, la sociedad sea la primera llamada a cumplir con la obligación de un tercero.

Sin embargo, nuevamente nos preguntamos ¿si es realmente justificable que exista una prohibición tan general como muestra la redacción de ésta?, o ¿si es válido señalar que la prestación de garantías depende de la conveniencia de cada caso en particular?

Por ejemplo, si un tercero desea adquirir un porcentaje mayoritario de las acciones de la sociedad de un accionista saliente y, para tales efectos, solicita un préstamo para obtener los flujos suficientes para adquirirlas y el prestamista, por supuesto, le solicita la constitución de una garantía que respalde el pago, ¿qué tendría de malo que sea la misma sociedad quien lo garantice? Es posible que, con el ingreso de este nuevo accionista controlador, quien además será quien nombre a la mayoría de los

otorgue préstamos (lo cual ni siquiera se registraría en el estado de situación porque se trataría de una contingencia) pero no dice nada respecto a que asuma un pasivo.

No obstante lo anterior, aunque no se trate de una situación expresamente contemplada por la norma, es probable que la doctrina considerase que la operación descrita en nuestro último ejemplo constituye asistencia prohibida por el artículo106 de la Ley General de Sociedades (p. 262). 
miembros del directorio, la sociedad tenga mejores resultados como consecuencia de la nueva gestión y la garantía prestada por la sociedad generará beneficios y no perjuicios.

\section{A.3) Sobre el otorgamiento de préstamos con la garantía de las acciones de propia emisión de la sociedad:}

En este caso, nos encontramos en el siguiente supuesto: La empresa Estudiosos S.A.C. le otorga un préstamo a uno de sus accionistas, Fabio Picapiedra y éste, a efectos de garantizar la devolución del préstamo, constituye una garantía mobiliaria a favor de la empresa sobre las acciones de las cuáles es titular en la misma empresa.

Claro, en ese ejemplo, el inconveniente más grande es que si el accionista incumple con el repago del préstamo, Estudiosos S.A.C. deberá ejecutar la garantía y adjudicarse las acciones objeto de la garantía. Como consecuencia de la ejecución de la garantía, Estudiosos S.A.C. se encontraría ahora en la obligación de cumplir con las disposiciones del artículo $104^{\circ}$ de la Ley, que se refiere a la autocartera o a la adquisición por la sociedad de sus propias acciones.

Asimismo, como bien lo hemos señalado en la parte doctrinaria del presente artículo el incumplimiento del deudor y la adjudicación de las acciones a favor de la propia sociedad también significaría una suerte "devolución de aportes encubierta" sin cumplir con las condiciones estipuladas por la Ley.

\section{A.4) Sobre el otorgamiento de garantía con garantía de acciones propias de la sociedad:}

Siguiendo a lo indicado por los profesores Guillermo Ferrero y Antonio Guarniz (2015, p. 265), cuando intentamos entender sobre los alcances de este supuesto prohibitivo de asistencia financiera, podemos interpretar que existen dos situaciones:

- La primera situación que se podría entender es que la sociedad no puede aceptar garantías constituidas por acciones de su propia emisión, pero esta prohibición es la misma que se explicó en el punto anterior. Por lo tanto, esta primera interpretación no podría ser la adecuada puesto que estaría siendo regulada dos veces. 
- La segunda interpretación que correspondería es que la sociedad otorgue las acciones que mantiene en cartera como garantía para respaldar cualquier obligación que la sociedad asuma.

\subsection{2 ¿Los Leveraged buyouts califican como Asistencia Financiera prohibida?}

\section{Una breve introducción a los Leveraged buyouts:}

Volvamos al comienzo de nuestro trabajo, exactamente la parte introductoria cuando hicimos mención a una a estructura societaria-financiera que ya lleva bastantes años en el mercado y que se desarrolló principalmente en los Estados Unidos de América, el denominado leveraged buyout o "LBO".

Varios autores alrededor del mundo han utilizados sendos medios para explicar el detalle el funcionamiento del LBO y su utilización como herramienta para concretar la toma de control de las empresas. Particularmente, los autores hacen mención a su existencia como una figura financiera y jurídica importante cuando se desarrollan los conceptos de las transacciones de private equity.

De esta manera, por ejemplo, Hernández y Escribens (2004) definen a las transacciones de private equity de la siguiente manera:

Las transacciones private equity tienen como objeto principal la inversión en acciones o valores similares de sociedades cerradas o privadas, entendiendo por tales a aquellas que no tienen valores listados en bolsa y que requieren una fuerte inyección de dinero con el fin de continuar su proceso de desarrollo y crecimiento y que eventualmente tiene activos subvaluados.

Esa inyección de dinero tiene como contrapartida para el inversionista (que en el mercado de hoy son, básicamente, fondos de inversión) la adquisición de acciones o de un valor similar que le permita tener una participación en la rentabilidad de negocio (p. 282).

Explicando este tipo de transacciones, los autores antes mencionados, Hernández y Escribens (2004) introducen la idea del LBO así:

Normalmente, la inyección de dinero por parte del fondo de inversión, o el inversionista que sea, tiene su origen en una combinación de capital propio (equity) y de préstamos 
(deuda) obtenida de instituciones financieras, siendo que, entonces, muchas de estas estructuras tienen un grado de apalancamiento relativamente importante. Con el fin de reducir el margen de riesgo en la inversión, el apalancamiento vía deuda suele afrontarse con los propios recursos de la sociedad objeto, surgiendo ahí los denominados leveraged buyouts ( $L B O)$ [cursiva añadida].

(...) hay un grupo importante de operaciones de private equity donde los fondos de inversión combinan capital y deuda en la adquisición, con la participación de una institución financiera, involucrando a los administradores como inversionistas como un co-inversionistas (produciéndose un MBO) y apalancando la porción de deuda en la adquisición con los propios recursos de la sociedad objeto (utilizando un LBO) (p.284.).

Asimismo, se debe mencionar, que en las transacciones de private equity se distingue de la inversión de fondos especializados que están interesados en invertir en una sociedad pero que NO desean ser los accionistas controladores, solo formar parte de la sociedad con un paquete accionario significativo a través del cual logran obtener un rédito dentro de un periodo de corto o mediano alcance ( 3 o 5 años, por ejemplo).

En la clase de inversión de private equity antes mencionada, no se ve involucrado una toma de control, solo la adquisición de una participación de la sociedad objetivo.

Siguiendo esa línea de pensamiento, se puede señalar que el LBO significa no un simple mecanismo de inversión, sino un mecanismo a través del cual se busca (y se consigue) la toma de control de una sociedad objetivo y cuya característica más importante es que la sociedad objetivo es la que soporta la carga financiera en virtud a la cual se consiguió la toma de control, como ya se mencionará en las líneas siguientes.

Sin embargo, también es importante indicar, como bien lo hace Eduardo López Sandoval (2004, p. 252), no toda toma de control significa la utilización de la figura del LBO, ya que la señal particular de esta figura es que la toma de control implique que la financiación se realice vía la utilización de la deuda. Es debido a esta característica esencial y particular de los LBO que su denominación en castellano es "COMPRA APALANCADA".

La característica principal de la figura del LBO presentada por López Sandoval (2004, p. 253) y es desarrollada de la siguiente manera: 
(...) vemos por ejemplo, si las deudas incurridas para la operación son repagadas con fondos propios del inversionista o con fondos proporcionados por terceros ajenas a Target [la sociedad objetivo] no nos encontramos frente a un LBO. Para que ello ocurra, el repago de la deuda incurrida debe necesariamente efectuarse con flujos provenientes, directa o indirectamente, de la propia empresa adquirida. Así, se sostiene que, en puridad, solo estaremos frente a una operación de LBO "en la medida en que los compromisos de pago contraídos frente a terceros por los compradores para materializar la adquisición sean trasladados a la sociedad adquirida y entren a formar parte de su pasivo exigible ${ }^{11}$ [cursivas añadidas] (...).

Entonces, después de todo lo presentado, podemos resumir que en el mundo de las adquisiciones de sociedades, en el cual se necesita a un comprador o a un inversionista interesado en una sociedad objetivo, también denominada como "TARGET" para muchos autores (incluyendo a nuestro autor guía López Sandoval), existe una estructura exportada de la realidad norteamericana, que se denominada LBO y que para exista como tal, dicha estructura debe suponer la toma de control de la sociedad TARGET (objetivo), el financiamiento de dicha toma de control a través de "deuda", la cual implica un valor sumamente alto de la financiación del precio y, por último, no siendo más importante, dicha deuda (para concretar la toma de control de la sociedad TARGET), debe ser asumida por TARGET, directa o indirectamente.

$\mathrm{Al}$ analizar esta recapitulación, podemos darnos cuenta desde ya porque los autores y expertos en derecho financiero y corporativo señalan que el LBO resulta ser una forma de asistencia financiera, que en nuestra legislación peruana resulta prohibida, de acuerdo a los supuestos consignados en el artículo $106^{\circ}$ de LSG. $^{\mathrm{Al}}$ final de cuentas, es la sociedad objetivo la que termina soportando el peso financiero y legal de la deuda tomada por el inversionista - a través de cualquier vehículo jurídico para lograr la adquisición de acciones o participaciones en la sociedad objetivo y así lograr tomar el control (“take over”, en su denominación en inglés).

La explicación de esta figura resulta, a veces, un poco compleja, pues ciertamente lo es, tanto jurídica como financieramente. Recordemos que, en las tomas de control, en el $99 \%$ de los casos, el comprador no tiene los fondos totales para logra la adquisición

\footnotetext{
${ }^{11}$ Para estos efectos, López Sandoval cita la obra de Martin Aurioles denominada "Leveraged buy-outs en derecho español de sociedades anónimas", En Revista de Derecho Bancario No. 51, edición JulioSeptiembre de 1993.
} 
de las acciones de la sociedad objetivo o, simplemente, no quiere poner "todos sus huevos en una sola canasta" y a efectos de diversificar el riesgo y, también, de invertir parte de dichos fondos en otro negocio (tal vez menos azaroso), prefiere prestarse el dinero que le servirá para adquirir esta participación tan deseada en la empresa objetivo.

En la práctica, como bien los señalan los autores de la materia, especialmente López Sandoval (2004), un LBO se materializa, por ejemplo, bajo las siguientes estructuras más representativas:

\section{A) Vía Fusión:}

El inversionista está interesado en la sociedad objetivo, frecuentemente llamada en la literatura jurídica como TARGET. Por su parte, los accionistas de TARGET están interesados en escuchar la oferta del inversionista.

Siguiendo la debida diligencia, ambas partes firman una carta de intención, con una cláusula de confidencialidad incluida, y permiten que el inversionista realice una auditoria legal-financiera a TARGET a efectos de determinar su valor, el cual es resultante una serie de factores importantes para determinarlo, como lo son la relación de sus activos principales, pasivos y contingencias tributarias, judiciales y financieras.

Después del resultado de la auditoría, el inversionista decide que se encuentra interesado en tomar el control de TARGET.

El inversionista, como buen empresario, tiene una serie de inversiones y sabe que tiene que diversificar para diluir el riesgo de pérdidas. Por lo que, al analizar su caja, decide que sólo va a disponer el 30\% de la misma para pagar el precio de las acciones de TARGET y que el $70 \%$ restante lo financiará mediante un préstamo bancario.

El inversionista, por su supuesto, al tener un historial crediticio interesante, consigue un banco que acepte prestarle el dinero ya que, éste también ha hecho un análisis de TARGET y considera que el mercado le permitirá tener réditos interesantes. Claro está que el banco solicitará el otorgamiento de una serie de garantías por parte del inversionista y por parte de la misma TARGET (después de la toma de control), además de una serie de obligaciones y responsabilidades financieras importantes.

El inversionista - persona natural o jurídica, nacional o extranjera - constituye una sociedad nueva de la cual es el accionista mayoritario (o el único accionista) o un 
Special Purpuse Vehicle - SPV; para los efectos de este supuesto llamémosla NEWCO (como la gran mayoría de autores nacionales y extranjeros la llaman).

NEWCO y el banco celebran un contrato de préstamo en el cual NEWCO se obliga a cumplir con una serie de obligaciones legales y financieras, así como al otorgamiento de una serie de garantías a favor del banco. Quizás la obligación más importante es que NEWCO se fusione con TARGET, pero sobre esta particularidad ahondaremos más adelante.

NEWCO y los accionistas mayoritarios, digamos los que representan más del 95\% del porcentaje accionario de TARGET, celebran un contrato de compraventa de acciones a través del cual NEWCO adquiere la participación mayoritaria de TARGET. El banco, claro está, ha revisado dicho contrato y es el supervisor del mismo a efectos de ejecutar la segunda parte de la operación.

Una vez obtenido el control de TARGET, NEWCO - como accionista mayoritario del mismo - aprueba mediante junta general de accionistas que NEWCO y TARGET se fusionen, conforme a lo estipulado en el artículo $344^{\circ}$ de la LGS.

Tal y como lo mencionaba López Sandoval (2004) en esta fusión entre NEWCO y TARGET pueden concretarse dos escenarios, que (i) MEWCO absorba a TARGET o que (ii) TARGET absorba a NEWCO, conforme el mismo lo detalla a continuación:

La fusión en cuestión puede efectuarse bajo dos modalidades, a saber: (i) Forward Merger LBO, por la cual NEWCO absorbe a TARGET, de modo tal que la totalidad del patrimonio de la segunda es trasladado a la primera, con la consiguiente extinción de la personalidad jurídica de TARGET; y (ii) Reverse Merger LBO, con el consiguiente traslado de todo el patrimonio de la primera (incluyendo la gran deuda contraída para la adquisición) a la segunda (p. 255).

En cualquiera de las 2 modalidades mencionadas por el autor antes referido, la misión más importante se ha cumplido, que TARGET lleve en sus espaldas la carga financiera del crédito bancario. Así, si TARGET absorbe a NEWCO, la primera se convertirá en el titular y obligado de la deuda tomada por NEWCO y su patrimonio servirá de garantía de pago frente al banco. Por otro lado, si NEWCO absorbe a TARGET, NEWCO terminará pagando el préstamo bancario directamente, y lo hará con los flujos dinerarios obtenido del buen desarrollo del objeto social de ésta y garantizando dicho pago con su patrimonio. 


\section{B) Vía transferencia de fondos:}

En este caso, la figura del pago diferido entra a colación. Es decir, NEWCO negocia con los accionistas mayoritarios de TARGET para pagar una parte del precio de su porcentaje accionario con el dinero que tenga disponible, ya sea que éstos prevengan de los aportes de inversionista, accionista de NEWCO o que provengan de un préstamo a corto plazo.

Una vez que se haya cerrado el contrato de compraventa de acciones y NEWCO se vuelva accionista mayoritario de TARGET, mediante aprobación vía Junta General de Accionistas, TARGET aprobará la obtención de un préstamo, para lo cual tendrá todo su patrimonio para respaldar el mismo. Una vez desembolsado el mismo, TARGET le transferirá el dinero a NEWCO (López Sandoval, 2004, p. 256) (i) vía pago de dividendos, (ii) distribución de reservas de libre disposición o (iii) mediante un mutuo efectuado de su subsidiaria a su matriz.

\section{C) Vía liquidación:}

En este caso, NEWCO, ya con los fondos necesarios para hacerse de las acciones de TARGET y convertirse en el accionista mayoritario o en el único accionista de la misma; dichos fondos han sido obtenidos mediante un contrato de préstamo u otra forma de financiamiento.

En ese sentido, ya NEWCO se encuentra en capacidad para celebrar el contrato de compraventa de acciones respectivo. Una vez adquiridas las acciones, mediante Junta General de Accionistas de TARGET, NEWCO aprueba la disolución y liquidación de áquella para que, una vez que se haya pagado a los acreedores de la misma, el haber social resultante, es decir, todos los activos y flujos dinerarios existentes en la contabilidad de TARGET, se distribuyan a NEWCO como único accionista de TARGET y, TARGET se extinga definitivamente.

Al obtener NEWCO el haber social resultante de TARGET, aquel cumplirá con pagar el préstamo obtenido para hacerse de TARGET con los medios derivados del haber social de la extinta TARGET.

Entonces, ¿los leverage buyouts califican como Asistencia Financiera?: 
Si volvemos al artículo $106^{\circ}$ de la LGS, es claro que la prohibición de la asistencia financiera recogida a dicho artículo inhibe a la realización de varios comportamientos los cuales se han cumplido con detallar anteriormente en el presente trabajo.

Si nos concentramos en las figuras de LBO que se han estudiado anteriormente, podemos notar que los LBO podrían recaer en la figura de asistencia financiera prohibida porque se podría entender que se estaría perforando el espíritu de la norma indirectamente.

Me explico. Desde un inicio establecimos que la redacción de artículo $106^{\circ}$ de la Ley no es la más feliz, adicionalmente resulta un poco problemático establecer con claridad los supuestos de asistencia financiera prohibida. Sin embargo, si podemos decir que lo que busca la norma es que la sociedad objetivo no ponga en riesgo la integridad del capital social ni de los derechos de los otros accionistas de la sociedad objetivo (TARGET), al aceptar el otorgamiento de préstamos y/o de garantías, con la garantía de sus propias acciones y, especialmente, para la adquisición de acciones de emisión de la propia sociedad objetivo.

Es nuestra opinión que el LBO no encaja directamente en el molde impuesto - de forma poco clara- por el legislador societario, pero sí podrían encajan de forma indirecta en la norma.

Es decir, por ejemplo, en el LBO vía fusión, el préstamo fue otorgado a NEWCO pero, una vez aprobado el proceso de fusión entre TARGET y NEWCO bajo cualquiera de las modalidades antes presentadas, al final de cuentas, TARGET es quien termina financiando el emprendimiento de NEWCO y de su inversionista y su afán de hacerse de una compañía. Y, así, lo mismo podría interpretarse en el LBO vía transmisión de fondos y el LBO vía liquidación.

Indirectamente, podríamos creer que se está vulnerando el aparente espíritu de la norma del $106^{\circ}$ de la LGS, pues se está concretando por la vía indirecta, lo que no se puede hacer por la vía directa.

A ver, si TARGET le presta a NEWCO para comprar acciones de su propia emisión, que en dicho momento son de titularidad de un accionista X; o, sí, el accionista $\mathrm{X}$ da en garantía las acciones de su propiedad emitidas por TARGET para garantizar un préstamo otorgado por la misma TARGET, resulta evidente que se estaría incurriendo 
en asistencia financiera prohibida de manera directa $y$ sin valerse de ninguna estructura elaborada para hacerlo.

Por supuesto, la determinación del hecho que se está infringiendo una norma de manera directa o indirecta depende del método interpretativo que se esté usando. Me explico. Muchos autores y abogados emiten su opinión legal sobre la "legalidad" de los LBO en función de la perspectiva desde la cual se está analizando la operación en particular.

Es así que, por ejemplo, Ferrero y Guarniz (2015, p. 262) son del pensamiento que el estudio y la interpretación de las operaciones que podrían caer en los supuestos del artículo $106^{\circ}$ de la LGS presentan para los intérpretes del derecho una gran disyuntiva. Así, ellos señalan lo siguiente:

El artículo $106^{\circ}$ de la Ley General de Sociedades es una de esas normas en las que existe una tensión entre la interpretación lógica de la norma y la interpretación restrictiva que debe hacerse de cualquier disposición que restringe derechos. (...)

Asimismo, Ferrero y Guarniz (2015) también señalan:

Así, dado que existen muchas vías para llevar a cabo la asistencia financiera y dado que varias de ellas nos llevan a la misma, o prácticamente la misma, situación económica, la pregunta de fondo es si es que estas vías alternativas son legales o no. Si el operador del Derecho a quien corresponde tomar una decisión sobre un caso concreto (juez, árbitro u otro) se apega a una lectura más literal y restrictiva del artículo 106, debería concluir que las vías alternativas son legales. Si, por el contrario, su manera de interpretar el 106 es más amplia, podría concluir que las vías alternas constituyen fraude a ley o abuso de derecho [cursivas añadidas] (p. 263).

Claro está que existe una discrepancia entre las normas interpretativas que se deben aplicar al momento de estudiar una estructura legal que podría caer en un supuesto de asistencia financiera prohibida que se encuentra recogida en el artículo $106^{\circ}$ de la LGS. Así pues, resulta difícil elegir nuestra posición cuando nos debatimos entre: (i) el principio de legalidad, es decir, ceñirnos a los supuestos exactamente descritos y, por lo tanto, aplicar lo que señala el artículo IV del título preliminar del Código Civil peruano que estipula que "la ley que establece excepciones o restringe derechos no se plica por analogía" o (ii) aplicar el principio del fraude a la ley." 
Sobre la aplicación del principio del fraude a la ley y de la analogía, López Sandoval (2004) también cumple con señalar lo siguiente:

Querer extender los efectos de dicha prohibición a otras operaciones similares a las expresamente mencionadas en la antedicha norma parecería contravenir flagrantemente el principio general contenido en el artículo IV del Título Preliminar del Código Civil (...).

En suma, siguiendo la línea trazada por la jurisprudencia española (...) tenemos que los requisitos establecidos para que una determinada operación se considere realizada en fraude a la ley son dos: (i) que la misma se realice con arreglo a una norma que en principio la ampare; y (ii) que la intención de beneficiarse con ella genere un resultado prohibido por la ley (pp. 270- 271)

\section{El dilema persiste en nuestras mentes: principio de legalidad o principio del fraude}

\section{a la ley. iiCuál debemos aplicar?!}

Es difícil decirlo. En la práctica actual peruana, se dan muchas operaciones de LBO como las descritas anteriormente, especialmente el LBO vía fusión y el LBO vía transferencia de fondos, $\mathrm{y}$, en dichas estructuras, los asesores legales de los bancos (ya sean internos o externos) aprueban su legalidad y estiman que NO resultan ser operaciones altamente contingentes, tanto es así que los bancos cumplen con aprobar los contratos de crédito respectivos y a desembolsar los montos para que el inversionista (NEWCO) se convierta en el único o en el accionista mayoritariamente avasallante de TARGET. Claro está a que, al final de la segunda parte de la operación, el banco se encuentre que su préstamo ha sido garantizado con los flujos y los activos de TARGET y, que, por supuesto, al ser el inversionista una persona con capacidad crediticia y al encontrarse muy bien posicionado en la industria en la cual se maneje, este inversionista también garantizará el repago de dicho préstamo.

\subsubsection{Análisis de otras figuras que pueden calificar como Asistencia Financiera $\underline{\text { Prohibida }}$}

Tomando en consideración el debate en relación a la interpretación de las estructuras legales-financieras a efectos de determinar si las mismas resultan ser casos de asistencia financiera prohibida, resulta ilustrativo mencionar y explicar algunas experiencias reales 
de LBO $\mathrm{u}$ otras estructuras que al principio podrían parecer supuestos prohibidos pero que no lo son y que tribunales extranjeros se han pronunciado declarando tal hecho.

Los siguientes casos serán explicados utilizando a nuestros protagonistas anteriores TARGET y NEWCO.

\section{A) Primer caso: Distribución de dividendos post adquisición de acciones}

Siguiendo nuestra ejemplificación, nos encontramos en el supuesto que NEWCO ya tomó el control de TARGET y tiene que cumplir con sus obligaciones financieras y pagar el préstamo bancario que recibió para tales efectos.

Ya en su posición de único accionista o accionista mayoritario, NEWCO aprueba vía Junta General de Accionistas de TARGET la distribución de dividendos o de resultados acumulados a su favor $\mathrm{y}$, con esos flujos, cumple con pagar el préstamo bancario, de acuerdo a su conveniencia.

Este caso no ha sido catalogado como asistencia financiera prohibida por la doctrina y jurisprudencias extranjeras (López Sandoval, 2004).

Sin embargo, consideramos que es válido precisar que la oportunidad y la observancia de las normas societarias son indispensables para la figura materia del presente punto.

Por ejemplo, ¿cambiaría el escenario de la utilización de la distribución de dividendos una vez ejecutada la compraventa de acciones se realice un día después mediante la distribución de resultados acumulados?

En mi opinión, esta situación no calificaría como asistencia financiera, analizado bajo el principio de legalidad y de estricto cumplimiento de los supuestos contenidos en el tipo legal societario.

\section{B) Segundo caso: Distribución del haber social y pago del precio de las acciones}

Siguiendo esta modalidad ya explicada anteriormente. Una vez que NEWCO adquiere el porcentaje mayoritario o la totalidad de las acciones de TARGET, NEWCO puede aprobar la disolución y liquidación de TARGET aparándose en el inciso 8 del artículo $407^{\circ}$ de LGS, el cual estipula que "La sociedad se disuelve por las siguientes causas... 
(8) Acuerdo de la junta general de accionistas, sin mediar causa legal o estatutaria alguna $(\ldots) "$

Una vez aprobada disolución de TARGET, durante todo el proceso de TARGET EN LIQUIDACIÓN, se cumpliría con pagarle a los acreedores, de acuerdo a lo estipulado por la LGS; y, NEWCO podría atribuirse el haber social remanente de TARGET. Con ese haber social, NEWCO podrá cancelar o amortizar los pagos del préstamo bancario en el cual incurrió para poder hacerse del control de TARGET.

Asimismo, como bien lo señala López Sandoval (2004, p. 274), de existir accionistas minoritarios todavía en TARGET junto con NEWCO, éstos, por supuesto, también tendrían derecho a beneficiarse del haber social remante de TARGET, por lo tanto, sus derechos como accionistas no se verían afectados

\subsection{Algunas conclusiones preliminares a manera de recapitulación}

A continuación, presentaremos algunas conclusiones preliminares sobre el presente capítulo:

- En primer lugar, debemos señalar que la lectura y la interpretación de la norma $106^{\circ}$ de LGS no son las más fáciles de obtener. Sin embargo, consideramos que son 4 las prohibiciones contenidas en dicha norma: la sociedad no puede (i) otorgar préstamos para la adquisición de acciones de su propia emisión; (ii) otorgar garantías para la adquisición de acciones de su propia emisión; (iii) otorgar préstamos con la garantía de sus propias acciones u (iv) otorgar garantías con la garantía de sus propias acciones.

- Sobre dichas prohibiciones, muchos autores han esbozado las debidas motivaciones que podrían haber llevado al legislador societario a establecer las mismas, como puede ser la protección de la integridad del capital social; la protección de los accionistas minoritarios; la protección de la sociedad misma como un ente económico que gobierna y protege sus propios intereses o simplemente que resulta injusto que la sociedad apoye los intereses de algunos socios sacrificando los intereses de los demás socios o de la misma sociedad. 
- Dentro del panorama que presente esta norma, se encuentra claro está lo acontecido en el extranjero, que, al fin y al cabo, es lo que hemos importado al momento de redactar esta norma.

- En el extranjero, pese a las limitaciones que también se han desarrollado alrededor de la asistencia financiera, se han desarrollado figuras financieras-legales que, sin ninguna duda, se han creado para que el inversionista más eficiente en el mercado y el que, se acuerdo a la proyección de sus flujos futuros, debería tomar el control de una sociedad TARGET y volverla más exitosa y eficiente. Para tales efectos, se ha creado la figura de los leveraged buyouts o LBO.

- Estos LBO son generalmente aceptados en el mundo empresarial extranjero y, ciertamente en el peruano. Sin embargo, y especialmente estudiando el panorama nacional, la valla de la legalidad de estas operaciones es difícil de saltar ya que, las interpretaciones sobre la legalidad de estas operaciones no son todo claras y denotan un riesgo no tan bajo.

- A ver, resumimos la explicación de los LBO, lo podemos hacer diciendo que es una operación mediante la cual un inversionista busca la toma de control de sociedad TARGET mediante un estructura legal y financiera tal que la sociedad TARGET es la que terminará soportando la carga financiera de tal take over.

- A efectos de ejemplificar las modalidades de los LBO, hemos explicado los más comunes en el mercado. Estos son: (i) LBO vía fusión; (ii) LBO vía transmisión de fondos de libre disposición y (iii) LBO vía liquidación del patrimonio de TARGET.

- Sobre el particular, se ha logrado concluir que los LBO vía transmisión de fondos de libre disposición y los LBO vía liquidación del patrimonio de TARGET definitivamente no encajan en nuestras prohibiciones del $106^{\circ}$ de LGS. Sin embargo, debemos decir que, según la jurisprudencia comparada europea, los tribunales sí encuentran que los LBO vía fusión y los LBO vía préstamo resultan infractores de la norma sobre asistencia financiera, claro está que esta lectura se realiza utilizando la interpretación del negocio en particular y mediante la aplicación del principio del fraude a la ley.

- En nuestro caso peruano, podemos decir que, en la actualidad se realizan múltiples operaciones bajo el esquema del LBO vía fusión y que los mismos son validados por los bancos, ya que, por lo general, se encuentra de por medio para la toma de 
control un préstamo bancario a favor del inversionista a través de NEWCO y que se encontrará condicionado a la posterior fusión de TARGET y de NEWCO, puesto que lo que más desean los bancos son los activos y los flujos de TARGET como garantía del repago de su préstamo.

- Al final del día, y tomando en consideración las opiniones de los autores que nos han ayudado a realizar el presente trabajo, en la actualidad, las estructuras que son utilizadas para las tomas de control deben ser miradas de una doble óptica: (i) caso por caso, es decir, que cada caso debe ser estudiado de forma individual de acuerdo a las circunstancias de los actores protagonistas del negocio (inversionista, TARGET y la estructura utilizada) y (ii) el principio interpretativo que se utiliza en cada operación, es decir, nuevamente nos quedamos en la disyuntiva si utilizar el principio de legalidad o el principio de fraude a ley.

- En ese sentido, a fin de aclarar el panorama legislativo peruano que nos aguarda cada vez que nos vemos forzados a estructurar un operación que involucre la toma de control vía compra apalancada, nuestro posición que debemos lograr la búsqueda de una reforma legislativa que acoja las justificaciones para la regulación de la asistencia financiera y las necesidades del mercado, que, claro está involucran que el inversionista más eficiente sea el que tenga la oportunidad de manejar los negocios con perspectivas más positivas en cada mercado. 


\section{CAPÍTULO II: ASPECTOS CRÍTICOS A LA FIGURA DE LA ASISTENCIA FINANCIERA}

2.1. Posibles justificaciones para la regulación de la figura de la Asistencia Financiera

Como sabemos, toda norma restrictiva o prohibitiva de derechos tiene su fundamento en la búsqueda de incentivos para procurar la protección de los derechos de unos sujetos en particular, en ese sentido, a continuación, presentaremos y desarrollaremos las teorías proteccionistas referidas en la doctrina y que se encuentran relacionadas a la regulación de la figura de la asistencia financiera. 


\subsubsection{Protección de la integridad del capital social de la compañía}

De acuerdo con lo regulado por la LGS peruana, ante un acuerdo de reducción de capital, la compañía debe publicar dicha decisión a efectos de que posibles acreedores puedan oponerse al mismo si consideran que dicha reducción afectará el cobro de sus acreencias.

En ese sentido, si la compañía brinda asistencia financiera, por ejemplo, en la modalidad de "otorgamiento de préstamos para la adquisición de sus propias acciones", se entiende que la compañía está disponiendo del patrimonio de ésta para facilitar la adquisición de sus propias acciones a favor de un tercero (entendiéndose por tercero a todo aquel ajeno a la sociedad), prefiriendo así esta clase de operaciones antes que cumplimiento de sus acreencias o en todo caso poniendo en peligro el monto de los flujos de caja de la sociedad así como el patrimonio de la ésta, los cuales, en principio, existen para asegurar el cumplimiento de las obligaciones contraídas por la sociedad.

Asimismo, si la compañía, por ejemplo, acepta como garantía las acciones de su propia emisión, ante un eventual incumplimiento, la compañía estaría recibiendo sus propias acciones como pago y el mismo que no representa un valor adicional puesto que la sociedad no puede ser accionista de sí misma y tendría que amortizar dichas acciones, conforme a lo establecido en el artículo $104^{\circ}$ de la LGS, por lo que ésta deberá necesariamente reducir su capital social, por lo que, al final, dicha ejecución no representa un pago propiamente dicho para la sociedad.

En relación a lo antes referido, López Sandoval (2004) ha señalado lo siguiente refutando así la presente teoría:

Cuando una sociedad adquiere acciones de su propia emisión debe necesariamente amortizarlas y reducir su capital social o, alternativamente, conservarlas en cartera cuando la adquisición se realiza con cargo a cuentas de libre disposición. Este mandato ha sido cuidadosamente diseñado para proteger la integridad del capital social, dado que, según lo que la teoría societaria plantea, no debe admitirse la devolución de aportes a los accionistas, sino únicamente bajo los mecanismos legales establecidos para proteger los intereses de acreedores: reducción de capital o distribución de cuentas libres.

Sin embargo, en el caso de la figura de la asistencia financiera, cuando una sociedad le otorga un préstamo a un tercero para facilitar la adquisición de sus 
acciones, no se produce una devolución indebida de aportes. Lo único que ocurre es una sustitución de cuentas en el lado activo del balance de la sociedad asistente: se intercambia el activo utilizado para brindar la asistencia financiera (ejemplo, dinero o valores) por una cuenta por cobrar al tercero beneficiado por la asistencia. La situación patrimonial de la sociedad tras la realización de dicha asistencia financiera permanecería inalterable y la relación entre el patrimonio neto y el capital social no sufriría variación alguna. El mismo razonamiento puede ser aplicado al caso de asistencia financiera prestada mediante el otorgamiento de garantías [cursivas añadidas] (p. 262).

Como se puede apreciar, la doctrina opina que la protección de la integridad del capital social detrás de la prohibición de la asistencia financiera no convence del todo, puesto que como lo señala López Sandoval (2004) en el extracto de su artículo antes citado, en puridad, al brindar asistencia financiera mediante el otorgamiento de un préstamo por ejemplo, no se suscita una disminución del capital social sino un intercambio de activos - dinero o valores - por una cuenta por cobrar.

Entonces, ante tal comprobación contable, podemos afirmar que efectivamente la teoría de la protección de integridad del capital social de la compañía como justificación a la prohibición de la asistencia financiera no tiene mayor asidero en la actualidad como quizás alguna vez lo tuvo en la Inglaterra de principios del siglo XX.

\subsubsection{Protección de los accionistas minoritarios de la compañía}

Asimismo, como es sabido, uno de los temas más relevantes que busca regular el derecho societario es el control o toma de decisiones de una compañía. Este tema es importantísimo pues el control de una sociedad no solo significa la tenencia de un paquete accionario importante, sino que dicha tenencia accionaria se traduce en la posibilidad del establecimiento de un quórum especial (el cual puede ser diferente al que señala la LGS) para la adopción de determinados acuerdos como la modificación del estatuto social o la elección de los integrantes del Directorio, es decir, las llamadas supermayorías.

En tal sentido, la pugna nacida del "enfrentamiento" de accionistas mayoritarios contra accionistas minoritarios por el control de la sociedad cobra mayor asidero legal ante la figura de la asistencia financiera, pues se entiende que, por ejemplo, ante la posibilidad que la sociedad objetivo termine cargando con el préstamo mediante el cual un tercero - vía el camino de la asistencia financiera - consiguió adquirir un paquete 
mayoritario de acciones sobre TARGET vulnera de alguna forma el desarrollo del objeto social de la compañía objetivo, el cual es obtener réditos para los accionistas en general y procurar el cumplimiento de sus obligaciones crediticias, más no para favorecer a un grupo de accionistas (mayoritarios) frente a otros (accionistas minoritarios).

Sobre este tema, los profesores Ferrero y Guarniz (2015) hacen referencia a lo siguiente:

La situación descrita es una de potencial abuso pero en muchos casos es posible que los intereses del accionista minoritario estén perfectamente alineados con la asistencia financiera [cursivas añadidas]. En otras palabras, se requiere evaluar las circunstancias concretas de la operación.

Esto se debe a que no sería correcto afirmar que el accionista minoritario le es indiferente la identidad del accionista mayoritario (es decir, el controlador) de la empresa. Por el contrario, al revalorizar su propia participación en la empresa el controlador hará que, en proporción, el accionista minoritario también gane. En consecuencia, es posible que sea del mayor interés del accionista minoritario el poder generar los mecanismos y brindar las facilidades necesarias para que un nuevo accionista mayoritario se haga del control de la empresa [cursivas añadidas] (p. 259).

Claro, lo que señala la doctrina antes citada es que, en estricto, no se puede afirmar que toda asistencia financiera involucra que siempre el accionista mayoritario va a resultar beneficiado debido que solo su proporción accionaria va a ser revaluada por el comprador interesado, dejando que la misma sociedad TARGET soporte la contingencia financiera - por ejemplo - de asumir el préstamo que le otorgó al comprador para adquirir el paquete accionario.

Lo que se trata de decir es que, tal y como lo manifiestan Ferrero y Guarniz (2015, p. 261) cuando un tercero tiene tanto interés en ingresar como accionista a una sociedad, motivo por el cual paga una prima de control sobre las acciones a adquirir, esta prima de control de igual forma beneficiará a los accionistas minoritarios, pues, cuando ellos quieran vender sus acciones, también tendrán como precedente la valorización utilizada para la compra del paquete accionario mayoritario o quizás, el accionista mayoritario que entró a la sociedad TARGET al gozar del control de la misma y poder designar a la administración de ésta, procure que se generen sinergias positivas y por ende, mayores réditos, lo cual, sin ninguna duda, generará un beneficio para 
$\underline{\text { los accionistas minoritarios, ya sea vía reparto de utilidades o mediante la }}$ valorización de la empresa en general, lo cual genera mayores posibilidades de que su proporción minoritaria valga más en el mercado.

En ese sentido, lo que se pretende concluir es que la teoría de la protección de los accionistas minoritarios para defender la prohibición de la asistencia financiera no es del todo cierta, pues lo correcto es que se analice caso por caso a fin de determinar si de verdad se ha producido una afectación a los derechos de los accionistas minoritarios el hecho que la sociedad (de alguna manera) facilite la adquisición de sus acciones por parte de un tercero, ya que, como lo ha señalado la doctrina antes referida, puede que en realidad la entrada de otro controlador procure un beneficio para la sociedad objetivo que, a la larga, va a beneficiar también a los accionistas minoritarios. Por lo tanto, esta teoría nos es del todo cierta cuando se analiza desde una perspectiva general y meramente superficial, satanizando de esta manera a la figura de la asistencia financiera.

\subsubsection{Protección de los acreedores de la compañía}

La tercera teoría detrás de la regulación y/o prohibición de la asistencia financiera es la protección de los acreedores de la sociedad objetivo. Esta teoría se encuentra ligada a la teoría de la integridad del capital social a fin de que éste sirva como garantía en favor de los acreedores de la sociedad.

Esta teoría se encamina casi por la misma línea de pensamiento. Se cuestiona que los medios de la sociedad sean utilizados para procurar el acceso de un tercero dentro de la sociedad objetivo para que se vuelva el controlador y, para colmo, que este tipo de ayuda pueda significar colocar a la sociedad en una situación financiera delicada pues tenga que soportar costos financieros ajenos o facilitar o garantizar el pago por dicho acceso de manera ajena a las condiciones de mercado.

Sin embargo, como bien los señalan los profesores Ferrero y Guarniz (2015) ante un posible conflicto de los intereses de la sociedad, los intereses de los acreedores y los propios intereses de los administradores (como el propio Directorio), los acreedores gozan del derecho de oposición dicha determinada operación que realizará la sociedad.

De esta manera, los autores antes mencionados manifiestan lo siguiente:

Desde luego, existen situaciones en las cuales el interés de la sociedad (como ente independiente) se contrapone irreconciliablemente con los intereses de sus socios 
[cursivas añadidas]. Por ejemplo, la escisión de la sociedad o su fusión (especialmente cuando la sociedad es absorbida) son casos en los que frecuentemente no existe forma de cautelar el interés social. No hay manera de sostener que la sociedad resulte beneficiada con su extinción o que resulte beneficiada con la pérdida de activos sin ninguna contraprestación (asumiendo que lo que se esciende es un bloque patrimonial positivo).

La solución del Derecho es que en estos casos en los que no es posible cautelar el interés social (porque la operación probablemente sólo tenga sentido desde el punto de vista de los intereses de los socios) es que la única decisión no pueda ser tomada únicamente por los administradores sino que deben participar los socios. En estos mismos casos, además, los acreedores tienen la posibilidad de manifestarse, ejerciendo su derecho de oposición. [cursivas añadidas] (p. 261).

Entonces, como podemos apreciar, la figura de la asistencia financiera es tan controvertida que se han desarrollado una serie de teorías en base a las cuales la doctrina y la jurisprudencia (sobre todo la inglesa) han respaldado su negativa a la viabilidad y aplicación de la misma.

Sin embargo, doctrina peruana autorizada como la antes mencionada ha manifestado claramente que, en la actualidad, no podemos evaluar la razonabilidad y la procedencia de la asistencia financiera desde una perspectiva general y panorámica, sino que debemos hacerlo caso por caso. Entendiéndose de ese modo que se debe analizar transacción por transacción a fin de que se verifique que la operación en concreto no daña los derechos de la propia sociedad TARGET o de los stakeholders de ésta, llámense a éstos últimos los accionistas (minoritarios), los acreedores de la sociedad o a terceros interesados. 


\section{CAPÍTULO III: POSIBLES ALTERNATIVAS PARA LA REGULACIÓN DE LA ASISTENCIA FINANCIERA EN LA LEY GENERAL DE SOCIEDADES}

\subsection{Fundamentos jurídicos y económicos en base a los cuales debe modificarse la regulación de la Asistencia Financiera en nuestra legislación societaria}

De acuerdo a lo señalado anteriormente, el objetivo del presente trabajo es realizar un análisis crítico a la redacción actual del artículo $106^{\circ}$ de nuestra LGS que acoge a la figura de la asistencia financiera así como determinar las razones por las cuales dicho artículo debe ser modificado a miras de esclarecer y delimitar el panorama societario en el cual nos encontramos y, en ese sentido, determinar si dicha norma brinda la seguridad jurídica suficiente para la realización de transacciones que involucren la compra de paquetes accionarios a través de distintos tipos de financiamientos, entre los cuales se encuentran las afamadas compras con apalancamiento o leveraged buyouts.

En relación a este punto, debemos resaltar que resulta evidente que ante una mala regulación - o lo que es peor - ante una regulación poco clara (como es nuestro caso), los sujetos de derecho nos encontramos en un panorama nublado que no nos permite actuar con seguridad y, por ende, no nos permite determinar a priori las - posibles contingencias que pueden resultar de la realización de una determinada operación que implique algún tipo de asistencia financiera; en resumen, genera inseguridad jurídica para los inversionistas, para la compañía objetivo y para sus stakeholders.

En esa misma línea, en el mundo de la adquisición de paquetes accionarios y de las tomas de control de compañías, una norma como la regulada en el artículo $106^{\circ}$ de la LGS resulta más que peligroso puesto que puede generar problemas legales y económicos que no solo afectan a una transacción en particular sino además el panorama económicofinanciero a nivel general.

Por otro lado, Ferrero y Guarniz han indicado que dicha figura es un medio sumamente utilizado en la actualidad y que en el Perú el uso de dicha figura se está proliferando cada vez. 
En específico, en el referido artículo, Ferrero y Guarniz (2015, p. 257) señalan lo siguiente:

Los inversionistas ven la asistencia financiera como una forma rentable (y, por lo tanto, atractiva) de adquirir empresas y destinan cada vez más recursos a este esquema de inversión. Esto da lugar a la proliferación de fondos de inversión especializados que desarrollan sus actividades privilegiando esta estructura de operación.

En el Perú operan varios fondos de inversión que desarrollan operaciones basados en la asistencia financiera de sus empresas objetivo. Incluso algunos de estos fondos son administrados por sociedades administradoras locales. En estos fondos, de hecho, participa la mayor parte de inversionistas institucionales, tales como administradoras de fondos de pensiones y compañías de seguros. No hay duda de que, también en el Perú, la adquisición de acciones cuya estructura descansa en la asistencia financiera de la empresa objetivo es una importante y creciente del mercado [cursivas añadidas].

En nuestra opinión, tanto en el derecho como en el tenis, no hay nada peor que una cancha con los límites borrosos, pues no es posible determinar si la pelota salió o entró en la cancha.

El mercado de las fusiones y adquisiciones es igual que un partido de tenis, es difícil determinar cuánto tiempo va a durar el cierre de una operación de este tipo, pues todo depende de las negociaciones, de la determinación y estimación de los activos y pasivos; de lo bonito, de lo feo y de lo oculto; del planteamiento de la estrategia de adquisición de acciones o de la toma de control; y, sobre todo, de la obtención del tipo de financiamiento adecuado, el cual dependerá básicamente del precio acordado y de la forma de pago del mismo. En ese sentido, si la cancha no está bien delimitada, no se puede jugar bien un partido por parte de ninguno de los jugadores. Esto mismo sucede entre el accionista vendedor y el comprador de las acciones de una sociedad TARGET y su partido jugado en la neblina creada por el artículo $106^{\circ}$ de la LGS.

Como bien sabemos, los inversionistas, por lo general, no cuentan con la totalidad de los recursos para la adquisición de líneas de negocios o de paquetes accionarios importantes de una compañía o de la totalidad de una compañía, por lo que se valen de 
las distintas formas de financiamiento existentes (internas y externas; bancarias, aportes de accionistas o mercado de valores; etc.) para cumplir con dicho objetivo; y, la elección de una de éstas opciones de financiamiento dependerá de aspectos tanto legales como financieros derivados de una evaluación minuciosa.

A razón de esta variedad de opciones de financiamiento es cuando entra a tallar la figura de la asistencia financiera, en específico el leveraged buyout o LBO; figura, que como ya hemos explicado en capítulos anteriores, se da cuando la sociedad objetivo termina siendo la pagadora de la deuda o del financiamiento en la que incurrió el comprador para adquirir las acciones de TARGET.

Tal y como lo señalan Ferrero y Guarniz (2015, p. 257), la asistencia financiera es un método cada vez más recurrente en el mercado nacional por lo que la regulación de la misma es medular a efectos de procurar la proliferación de ésta.

En adición a lo anteriormente referido por los expertos en el tema que nos atañe, a continuación, presentamos un listado - de elaboración propia - de los posibles problemas que, en nuestra opinión, se generan ante la actual regulación de la asistencia financiera bajo el artículo $106^{\circ}$ de la LGS. Así tenemos que:

(i) Frustra operaciones de adquisiciones de paquetes accionarios de empresas peruanas.

(ii) Dificulta la determinación y el cálculo de contingencias futuras involucradas en determinadas operaciones de compra de acciones y de financiamiento, pues, ante la poca claridad de la norma, no podemos estar cien por ciento seguros si algún stakeholder podría cuestionar la operación realizada alegando el uso de un supuesto de asistencia financiera prohibida y solicitar la nulidad de algunos de los actos jurídicos celebrados o la responsabilidad de los administradores.

(iii) Genera pronunciamientos contradictorios por parte de las autoridades y de la doctrina.

(iv) Genera costos de transacción elevados, reduciendo la rentabilidad que se estimó derivaría de la adquisición de paquetes accionarios y/o de otras formas de tomas de control de una empresa o de un negocio. 
(v) Reduce el abanico de posibilidades para la elección de otros tipos de financiamientos que pueden resultar beneficiosos para todos los accionistas y para la propia compañía.

(vi) Mantiene a un nivel poco desarrollado el mercado de las fusiones y adquisiciones.

(vii) Frena la generación de (posibles) sinergias positivas que se derivan de la adquisición de paquetes accionarios de una empresa y/o de la toma de control de ésta.

(viii) Entorpece el desarrollo económico del país al encarecer o prohibir determinadas operaciones de financiamiento.

(ix) Reduce - en términos generales - la inyección de flujos de capitales extranjeros en el país en forma de inversión en empresas de capitales peruanos.

En ese sentido y a manera de conclusión adelantada, podemos determinar que existen varias razones en mérito de las cuales es necesita de una modificación del artículo $106^{\circ}$ de la Ley. Con esta modificación no es que busquemos que el legislador peruano inicie una ola de desregulación en el mundo del derecho de las corporaciones, sino, lo que en realidad buscamos es que aclare el panorama de la asistencia financiera a efectos que: (i) desde el punto de vista legal, no haya inseguridad jurídica generada ante la oscuridad de la norma; y, (ii) desde el punto de vista económico, la norma actual no desincentive modalidades de asistencia financiera que resulten económicamente viables y jurídicamente sean protectoras de la sociedad objetivo y velen por los derechos e intereses de los stakeholders de dicha sociedad.

\subsection{Propuesta de modificación a la regulación de la Asistencia Financiera recogida por la actual Ley General de Sociedades}

Consideramos que, ante lo anteriormente expuesto, no cabe duda que lo que buscamos proponer es que se modifique la norma del artículo $106^{\circ}$ de la LGS peruana con miras a procurar un ambiente respaldado por la seguridad jurídica y la predictibilidad.

Sobre el particular, también otros entendidos del tema y expertos en derecho societario han señalado que se debe modificar el referido artículo, por ejemplo, así lo han 
manifestado los profesores Ferrero y Guarniz (2015) en su última publicación a la cual hemos hecho referencia en líneas anteriores.

Ferrero y Guarniz (2015) han propuesto la siguiente modificación legislativa sobre el artículo $106^{\circ}$ de la LGS:

\section{Artículo 106.- Préstamo y garantías que involucran acciones de propia emisión}

La sociedad puede otorgar préstamos, asumir deudas de terceros o prestar garantías para la adquisición de acciones de propia emisión. Tales operaciones sólo podrán ser celebradas u otorgadas con el acuerdo previo de la junta general de accionistas. Este acuerdo otorga a los accionistas de la sociedad el derecho de separación, conforme a lo regulado en el artículo 200 y a los acreedores de la sociedad el derecho de oposición conforme a lo regulado en el artículo 219.

Cuando la sociedad reciba en garantía acciones deberán ser computadas para efectos de los límites establecidos en el artículo 104.

Los directores son solidariamente responsables ante la sociedad y los terceros acreedores por los contratos, créditos, préstamos o garantías celebrados u otorgados con infracción de los establecido en este artículo (pp. 271 -272)

Como se puede apreciar en la propuesta legislativa realizada por los profesores Ferrero y Guarniz (2015) , ellos buscan incentivar el otorgamiento de créditos por parte de la sociedad objetivo a efectos de adquirir acciones de emisión de la propia sociedad pero estableciendo expresamente que dicho acuerdo debe ser adoptado por la junta de accionistas, es decir, que deben cumplirse con la aprobación de las mayoría necesaria de acuerdo a ley o de acuerdo al estatuto de la sociedad - para aprobar un acuerdo de esta naturaleza y, asimismo, crea dos derechos adicionales. Primero, le otorga el derecho de separación a los accionistas que se hayan opuesto a tal acuerdo (conforme al artículo $200^{\circ}$ de la LGS) y, segundo, le otorga el derecho de oposición a los acreedores de la sociedad (conforme al artículo $219^{\circ}$ de la LGS).

Adicionalmente, señalan que el directorio de la sociedad objetivo es responsable solidario por el incumplimiento de las obligaciones establecidas en la norma.

En ese sentido, ante nosotros tenemos una propuesta legislativa que tiene los siguientes objetivos claramente planteados: 
- Permitir el otorgamiento de asistencia financiera a través de: (i) el otorgamiento de préstamos; (ii) la asunción deudas de terceros y (iii) el otorgamiento de garantías, para la adquisición de acciones de propia emisión.

- Proteger a todos los accionistas por igual, es decir, mayoritarios y minoritarios, a través del otorgamiento del derecho de oposición.

- Proteger a todos los acreedores por igual, a través del otorgamiento del derecho de oposición.

- Proteger a la misma sociedad objetivo (TARGET), a través de la creación de la responsabilidad solidaria del directorio por el incumplimiento de las obligaciones reguladas en la norma (propuesta por los profesores).

\section{Nuestra propuesta legislativa:}

Como consecuencia de todo lo que hemos investigado en la doctrina nacional y extranjera, a continuación, presentamos nuestra propuesta legislativa de la asistencia financiera:

Artículo 106.- Asistencia financiera para la adquisición de acciones de propia emisión

De acuerdo a lo establecido en el estatuto de la sociedad y en la presente Ley, la Junta General de Accionistas podrá aprobar el otorgamiento de préstamos, garantías, así como cualquier otro tipo de asistencia financiera a favor de terceros, a efectos de que éstos adquieran acciones de propia emisión de la sociedad o de su sociedad dominante, previo informe favorable del Directorio. Para la aprobación de dicho acuerdo se requería el voto favorable del $75 \%$ (Setenta y cinco por ciento) de las acciones con derecho a voto.

El acuerdo que aprueba el otorgamiento de asistencia financiera anteriormente mencionado le otorga al accionista y a los acreedores de la Sociedad los derechos de separación y de oposición, respectivamente.

En el caso del ejercicio de separación, el Directorio deberá emitir un informe adicional en el cual se detallará a la Junta General de Accionistas: (i) El monto que se deberá pagar a los accionistas salientes y (ii) los recursos con cargo a 
los cuales se efectuarán, de acuerdo a las reglas señaladas en el artículo $200^{\circ}$ de la Ley.

Sin perjuicio de lo anterior, el Directorio declarará expresamente bajo juramento que su opinión favorable al otorgamiento de la asistencia financiera no estuvo viciada por conflictos de intereses, conforme a lo regulado en el artículo $180^{\circ}$ de la Ley y dejará expresa constancia sobre el ejercicio de los derechos de separación y de oposición ejercidos por los accionistas o acreedores de la sociedad, según corresponda.

El Directorio de la sociedad es responsable por la conveniencia de las recomendaciones plasmadas en el informe descrito en el primer párrafo de presente artículo, así como por el cumplimiento de los mandatos contenidos en el mismo ante la propia sociedad, los accionistas de ésta y los terceros de buena fe, conforme a las normas de responsabilidad que correspondan y que se encuentran contenidas en la Ley.

El acuerdo de otorgamiento de asistencia financiera se publicará tres (3) veces consecutivas, de acuerdo a las formalidades establecidas en la Ley.

Finalmente, el acuerdo de Junta General de Accionistas que aprobó el otorgamiento de la asistencia financiera deberá inscribirse en la partida registral de la sociedad, bajo sanción de nulidad, después de 30 (treinta) días contados a partir de la última publicación, de no haberse ejercido el derecho de oposición por ningún acreedor.

En nuestra propuesta legislativa antes plasmada buscamos cumplir con los siguientes objetivos:

a) El objetivo más importante, permitir la asistencia financiera dentro de la

$\underline{\text { LGS. }}$ Esta introducción, a nuestro parecer, no es más que el reflejo de la realidad peruana a la fecha. Como ya lo habíamos comentado, nosotros y nuestros autores citados, en la práctica, se vienen concretando operaciones complejas que, indirectamente, hacen posible la ayuda financiera para la adquisición de acciones por parte de la propia sociedad TARGET. En ese sentido, si el mercado nos está revelando que, en algunos casos, es eficiente que TARGET presta ayuda financiera para la adquisición de sus propias acciones, ¿por qué no regularlo de 
manera clara y así disipar la incertidumbre jurídica que se vive bajo la sombra del actual artículo $106^{\circ}$ de la LGS?

b) Ahora bien, por supuesto que nos vamos a encontrar con algunas opiniones que nos digan que es más fácil legalizar lo "informal”, pero nosotros no consideramos que la aceptación de la asistencia financiera sea un camino facilista para permitir que los empresarios, inversionistas y abogados busquen concretar sus operaciones. Al contrario, creo que la práctica legal actual y el apoyo de las entidades financieras como los bancos, han fortalecido los cimientos para que permitamos la asistencia financiera.

c) Mediante la "legalización" de la asistencia financiera, los agentes del mercado, llámense, los inversionistas, las empresas, los bancos, los accionistas (mayoritarios y minoritarios), los acreedores y los consumidores, encontrarán que sus recursos pueden ser mejor aprovechados, ya que los sujetos más eficientes del mercado podrán, de manera más directa, regulada de forma clara y legal, ingresar a las empresas TARGET y tener la posibilidad de crear sinergias positivas y generar más réditos.

d) Asimismo, regulando una práctica ya común en el mercado de las fusiones y adquisiciones, nos permite dilucidar nuestro panorama legal. Es decir, no solo es permitir la asistencia financiera, pero que la misma se encuentre bien regulada a efectos de que en las transacciones se pueda respetar a cabalidad la ley y proteger los intereses y los derechos de la (i) TARGET como un ente independiente; (ii) de los accionistas mayoritarios y minoritarios; (iii) de los acreedores y (iv) de los administradores de la TARGET.

e) Como se puede apreciar, en nuestra propuesta legislativa buscamos regular lo siguiente:

(i) Que los estatutos y pactos y convenios de accionistas de las sociedades, de ahora en adelante, se actualicen y busquen regular un posible escenario de asistencia financiera y creen normas internas de regulación que busquen proteger a la misma sociedad como un ente independiente y a los distintos tipos de accionistas y así, asegurar el respeto de sus derechos políticos y económicos. 
(ii) La publicidad de los acuerdos que favorezcan a la asistencia financiera. Debido a que, una de las principales justificaciones para la prohibición de la asistencia financiera han sido la protección de la integridad del capital social y del mercado en general, regulando la publicidad de la asistencia financiera a través de las publicaciones y la inscripción obligatoria de dicho acuerdo en la partida de TARGET, permite que los accionistas dispersos y los acreedores de TARGET se encuentren informados sobre el devenir de la sociedad a fin de poder proteger sus intereses.

(iii) Bajo la misma línea de pensamiento desarrollado en el punto (ii) anterior, la nueva regulación contempla los derechos de oposición y de separación en favor de los acreedores y de los accionistas, respectivamente. De esta manera, quien pueda ver vulnerado sus derechos, podrá manifestarlo y tomar las acciones respectivas dentro del plazo establecido.

(iv) Asimismo, y dada la relevancia económica de la asistencia financiera para TARGET, se ha establecido una mayoría especial para el acuerdo de Junta General de Accionistas que busca aprobar la asistencia financiera.

(v) Por otro lado, en la propuesta se regula que, en el caso que algún accionista decida ejercer su derecho de separación, es obligación del Directorio emitir un informe en el cual se detallará: (i) El monto que se deberá pagar a los accionistas salientes y (ii) los recursos con cargo a los cuales se efectuarán.

(vi) Regular la responsabilidad del directorio o del Gerente General, dependiendo del órgano de administración de la sociedad. Mediante esta regulación, los administradores serán más cuidadosos al momento de recomendar la asistencia financiera, analizando para tales efectos la información financiera necesaria que respaldará su apoyo o no apoyo a las operaciones que impliquen asistencia financiera.

(vii)Asimismo, buscamos resaltar la noción de conflicto de intereses que, en muchas ocasiones, es olvidado por los administradores. De esta manera, los directores y gerentes generales tendrán en mayor consideración que 
su mayor deber es para con la sociedad y no para complacer intereses personales. Esta precisión también la buscamos hacer bajo el contexto de las implementación y ejecución de los principios del buen gobierno corporativo, hoy exigidos por los stakeholders y por los organismos estatales e internacionales. 


\section{CONCLUSIONES}

- La figura de la asistencia financiera es sumamente importante para el derecho societario a nivel mundial, por lo tanto, la forma en la cual se encuentra regulada es aún más importante a fin de determinar a priori y con claridad el contexto legislativo exacto en el cual se desarrolla una operación legal determinada, así como las contingencias y los costos legales y financieros de las mismas.

- La tendencia mundial en relación a la asistencia financiera es la de regularla, más no prohibirla, ya que, debido a la experiencia y al desarrollo del derecho societario a lo largo de los años, se ha permitido comprobar que ésta es una herramienta muy útil para el mundo de las fusiones y adquisiciones, así como para el mundo de las finanzas. En ese sentido, se ha llegado un punto en la historia de las transacciones corporativas en el cual los sistemas legales más importantes han llegado a valorar esta figura, por lo que buscan que su regulación sea más laxa pero que busca proteger los derechos de los stakeholders y de los de la misma compañía objetivo.

- En el contexto actual de las operaciones de fusiones y adquisiciones a través de las cuales se busca adquirir un paquete accionario que represente el control de la compañía objetivo, los modelos legales más utilizados son las compras apalancas o leveraged buyouts. Estos modelos y la forma cómo son implementados pueden bordear o traspasar los límites prohibidos establecidos por nuestra norma societaria debido a la poca claridad de la norma actual (artículo $106^{\circ}$ de la Ley General de Sociedades); sin embargo, estos tipos de operaciones siguen siendo utilizadas dentro del mercado de fusiones y adquisiciones peruano.

- La norma societaria que regula a la asistencia financiera tiene una redacción oscura sobre la cual se esbozan distintas interpretaciones y, como consecuencia, generan un contexto de inseguridad jurídica y (puede) acarrear un desincentivo en el mercado sobre la implementación de determinadas operaciones y estructuras legales.

- En el estudio de la figura de la asistencia financiera en nuestro sistema legal, la doctrina peruana más autorizada ha señalado que los mitos en base a los cuales se buscó la prohibición de esta figura ya no tiene mayor asidero en la actualidad, puesto 
que la mayoría de la teorías que respaldan la prohibición de la asistencia financiera han queda un tanto desfasadas y sin fundamentos tan sólido debido a que se ha podido demostrar que existen derechos que recoge nuestra Ley General de Sociedades en base a los cuales se puede proteger a los accionistas minoritarios, a los acreedores y a la misma sociedad objetivo. Tales derechos son básicamente el derecho de separación para los accionistas y el derecho oposición para los acreedores.

- Dentro de nuestra investigación, hemos procurado explicar cuáles son las motivaciones detrás de la regulación prohibitiva actual de la norma $106^{\circ}$ de la Ley General de Sociedades. Para tales efectos hemos citado a los autores peruanos que más han escrito sobre la asistencia financiera y que lo ha hecho en momentos diferentes. Todos ellos esbozan unas opiniones muy sustentadas y completas sobre la figura y buscan estudiar la aplicación y uso de la misma en el mundo societario.

- En base a lo escrito por dichos autores, hemos podido concluir que la práctica del derecho societario-financiero hace casi una necesidad de vida o muerte mejorar la regulación actual de la asistencia financiera, a fin de proteger a todos los protagonistas del mercado: la sociedad objetivo, el inversionista, los acciones mayoritarios y minoritarios, los acreedores y a los administradores (Directorio y Gerencia General).

- Como consecuencia de nuestro estudio, hemos podido identificar a uno de los representantes máximos de la asistencia financiera, los leveraged buyouts o LBO. Entendiéndolos como aquella figura o estructura que busca que el inversionista o NEWCO tome el control de TARGET y que, al final, sea la misma TARGET quien soporte la carga y responsabilidad financiera.

- Nos hemos dado cuenta que el LBO ha estado desde ya bastante tiempo en nuestra realidad societaria; y que, dependiendo de su estructura legal (vía fusión, vía remanente de liquidación, vía préstamos o vía transmisión de fondos de libre disposición), dicha estructura podría pasar como asistencia financiera prohibida de acuerdo a nuestra actual Ley General de Sociedades.

- Asimismo, podemos concluir que es sumamente peligroso apoyar estructuras que tienen dificultades para pasar la vaya de la legalidad societaria, pese a que, en la 
actualidad, las entidades bancarias y los asesores legales las avalan como una práctica común en el mercado transaccional.

- Que, también resulta peligroso que, debido a la oscuridad del $106^{\circ}$ de la Ley, también tengamos dudas sobre el método interpretativo que debemos utilizar al momento de analizar la operación en concreto a efectos de comprobar si es o no es un supuesto de asistencia financiera prohibida.

- Y, que como consecuencia de todo lo anteriormente dicho, no nos cabe duda alguna que la norma societaria que regula la asistencia financiera debe, a toda costa, ser modificada ya sea para, seguir prohibiendo la asistencia financiera, o para permitirla. Cualquiera sea la opción legislativa, esta figura debe ser regulada de mejor forma a efectos de procurar garantizar el cumplimento de los derechos de los protagonistas del mercado.

- Es nuestra posición, de acuerdo a la propuesta legislativa antes desarrollada, que la asistencia financiera debe ser permitida como una señal normativa que afirma que el derecho debe adoptarse a la vida moderna. Como esta noción no quiere decir que la nueva norma deba ser totalmente laxa y sin controles, al contrario, la nueva norma debe ser permisiva de la asistencia financiera pero inflexible al momento de regular y exigir el cumplimiento de los derechos de la sociedad objetivo, de los accionistas mayoritarios y minoritarios y de los acreedores.

- Para tales efectos, hemos trabajado una propuesta legislativa, que, nuestro modo de ver, es adaptable al cuerpo normativo de la Ley General de Sociedades y recoge los mismos derechos que ya se encuentran regulados en dicha Ley, pero que se adaptan a las circunstancias que presente la asistencia financiera. Para tales efectos, hemos creado formalismos necesarios que buscan la equidad de los derechos de los protagonistas y la adaptación de la sociedad a los conceptos que son protegidos los principios del buen gobierno corporativo y la noción de conflicto de intereses en las administraciones de las sociedades. 


\section{RECOMENDACIONES}

- En primer lugar, se recomienda modificar la norma que regula a la asistencia financiera en el Perú y que se encuentra recogida por el artículo $106^{\circ}$ de la Ley General de Sociedades a fin de que con la nueva redacción de dicho artículo se establezcan supuestos de asistencia financiera prohibida o permitida mucho más delimitados y claros y así evitemos caer en especulaciones en relación a la interpretación de la norma.

- Teniendo en consideración la premisa antes mencionada, también se recomienda que si se llegase a modificar el artículo $106^{\circ}$ de la Ley General de Sociedades tal y como lo proponemos, que la nueva regulación establezca un régimen regulatorio de la asistencia financiera, más no un régimen prohibitivo como se da en la norma actual. Es decir, si como lo hemos venido señalando a lo largo del presente trabajo, la figura de la asistencia financiera es de suma utilidad para los procesos de toma de control de compañías, lo más eficiente sería desarrollar una normativa que regule y delimite pero que no restrinja al punto que se busque crear nuevas figuras mediante las cuales se logra la finalidad que en principio estaba prohibida por la norma actual.

- Asimismo, se recomienda que el legislador realice un estudio integral de la Ley General de Sociedades a fin de que logre establecer un sistema normativo armonioso con la asistencia financiera. De esta forma, podrá entender que ya existen muchas herramientas legales para proteger a los stakeholders y a la propia sociedad objetivo sin necesidad de crear una figura legal prohibitiva. 


\section{REFERENCIAS}

Companies Act (2006). Recuperado del sitio de internet de The National Archives: http://www.legislation.gov.uk.

Decreto Real No.262, Código Civil Italiano (16 de marzo de 1942). Recuperado del sitio de Internet del World Intellectual Property Organization: http://www.wipo.int.

Elías Laroza, E. (2015). Derecho Societario Peruano. La Ley General de Sociedades del Perú. Lima, Perú: Gaceta Jurídica.

Ferrero G. y Guarniz A. (2015). La Regulación de la Asistencia Financiera. Ius et Veritas, No. 50, 256-272.

Gaughan, Patrick. A. (2011). Mergers, Adcquisitions, and Corporate Restructurings. Hoboken, N.J: Wiley.

Hernández Gazzo, J. L. y Escribens Olaechea, J. (2007). Private Equity y Buyouts (MBO y LBO): análisis de ciertas estructuras bajo el derecho societario y tributario peruano. Derecho PUC, 281-324.

Hundskopf Exebio, O. (2012). Manual de derecho societario. Lima: Gaceta Jurídica.

Ley No. 26887, Ley General de Sociedades (9 de diciembre de 1997). Recuperado del sitio de internet del Sistema de Información Jurídica: http://spij.minjus.gob.pe/

López Sandoval, E. L. (2004). Leverages buyouts a la luz de la regulación societaria peruana sobre asistencia financiera prohibida. Advocatus, X, 247-284.

Manual Societario, tomo I (2011). Lima, Perú: Editorial Economía y Finanzas.

Real Decreto Legislativo 1/2010, Ley de Sociedades de Capital (2 de julio del 2010). Recuperado del sitio de internet Agencia Estatal Boletín Oficial del Estado: https://www.boe.es/buscar/act.php?id=BOE-A-2010-10544.

Rubio Correa, M. (2000). El Sistema Jurídico. Introducción al Derecho. Lima, Perú: Pontificia Universidad Católica del Perú.

Satrústegui B. (2001). Adquisiciones especiales (II). En Régimen Jurídico de la Adquisición de Empresas, Editorial Aranzadi. Navarra.

Vaquerizo Alonso, A. (2003). Asistencia financiera para la adquisición de acciones propias. Madrid, España: Civitas. 